\title{
Review \\ Do Iron Oxide Nanoparticles Have Significant Antibacterial Properties?
}

\author{
Sergey V. Gudkov ${ }^{1, *(\mathbb{C})}$, Dmitriy E. Burmistrov ${ }^{1}$, Dmitriy A. Serov ${ }^{1}$, Maksim B. Rebezov ${ }^{1,2}{ }^{\mathbb{D}}$, \\ Anastasia A. Semenova ${ }^{2}$ and Andrey B. Lisitsyn ${ }^{2}$ \\ 1 Prokhorov General Physics Institute of the Russian Academy of Sciences, 119991 Moscow, Russia; \\ dmitriiburmistroff@gmail.com (D.E.B.); dmitriy_serov_91@mail.ru (D.A.S.); rebezov@yandex.ru (M.B.R.) \\ 2 V.M. Gorbatov Federal Research Center for Food Systems of the Russian Academy of Sciences, 109316 \\ Moscow, Russia; a.semenova@fncps.ru (A.A.S.); info@fncps.ru (A.B.L.) \\ * Correspondence: s_makariy@rambler.ru; Tel.: +7-499-503-8734
}

check for updates

Citation: Gudkov, S.V.; Burmistrov, D.E.; Serov, D.A.; Rebezov, M.B.; Semenova, A.A.; Lisitsyn, A.B. Do Iron Oxide Nanoparticles Have Significant Antibacterial Properties?. Antibiotics 2021, 10, 884. https:// doi.org/10.3390/antibiotics10070884

Academic Editor: Hao Song

Received: 23 June 2021

Accepted: 18 July 2021

Published: 20 July 2021

Publisher's Note: MDPI stays neutral with regard to jurisdictional claims in published maps and institutional affiliations.

Copyright: (c) 2021 by the authors. Licensee MDPI, Basel, Switzerland. This article is an open access article distributed under the terms and conditions of the Creative Commons Attribution (CC BY) license (https:// creativecommons.org/licenses/by/ $4.0 /)$.

\begin{abstract}
The use of metal oxide nanoparticles is one of the promising ways for overcoming antibiotic resistance in bacteria. Iron oxide nanoparticles (IONPs) have found wide applications in different fields of biomedicine. Several studies have suggested using the antimicrobial potential of IONPs. Iron is one of the key microelements and plays an important role in the function of living systems of different hierarchies. Iron abundance and its physiological functions bring into question the ability of iron compounds at the same concentrations, on the one hand, to inhibit the microbial growth and, on the other hand, to positively affect mammalian cells. At present, multiple studies have been published that show the antimicrobial effect of IONPs against Gram-negative and Gram-positive bacteria and fungi. Several studies have established that IONPs have a low toxicity to eukaryotic cells. It gives hope that IONPs can be considered potential antimicrobial agents of the new generation that combine antimicrobial action and high biocompatibility with the human body. This review is intended to inform readers about the available data on the antimicrobial properties of IONPs, a range of susceptible bacteria, mechanisms of the antibacterial action, dependence of the antibacterial action of IONPs on the method for synthesis, and the biocompatibility of IONPs with eukaryotic cells and tissues.
\end{abstract}

Keywords: nanoparticles; iron oxide; antimicrobial effect; green synthesis

\section{Introduction}

Nowadays, the application of nanotechnological solutions, such as the use of nanoparticles, is one of the promising ways to overcome antibiotic resistance in bacteria [1-5].

Nanoparticles (NPs) of several metals and their oxides, such as $\mathrm{Ag}, \mathrm{ZnO}, \mathrm{Fe}_{2} \mathrm{O}_{3}, \mathrm{Fe}_{3} \mathrm{O}_{4}$, $\mathrm{Al}_{2} \mathrm{O}_{3}, \mathrm{TiO}_{2}$, and $\mathrm{CuO}$, exert antibacterial action against Gram-negative and Gram-positive bacteria, as well as the antifungal action [6-14].

Iron is one of the most abundant elements on Earth and the fourth-most abundant element in the Earth's crust. Iron makes up more than $85 \%$ of the mass of the Earth's core and about $5 \%$ of the mass of the Earth's crust $[15,16]$. In living systems, iron is one of the key microelements. It has several important functions: it is a cofactor of several enzymes (catalase) and transport proteins (hemoglobin), ETC proteins (cytochromes and FeS proteins), and is necessary for DNA repair [17-20]. Iron is also found in the regulatory proteins of enterobacteria Salmonella enterica, including Fur, Fnr, NorR, SoxR, IscR, and NsrR [21-26]. Several bacteria can accumulate iron oxides in special organelles called magnetosomes-for example, Magnetospirillum magneticum [27]. It is assumed that they provide bacteria with the constant magnetic dipole, presumably for navigation purposes [28]. It was shown in Magnetospirillum magneticum wild-type and DmagA1/- that magnetosomes plays a key role in magneto-aerotaxis. Magneto-aerotaxis is the direct motion of bacteria downward in microaerobic environments favorable to growth [29]. 
Bacteria that use the iron oxidation reaction $\mathrm{Fe}^{2+}+0.25 \mathrm{O}_{2}+\mathrm{H}^{+} \rightarrow \mathrm{Fe}^{3+}+0.5 \mathrm{H}_{2} \mathrm{O}$ for energy generation and metabolism maintenance have been described. A minimum two groups of obligate iron-oxidizing bacteria: Betaproteobacteria and Zetaproteobacteria are described in the phylum Proteobacteria [30]. Iron is necessary for the proliferation of microbial agents of infectious diseases that developed ways for iron acquisition from the host, while the host has protective mechanisms preventing iron acquisition by microorganisms [30,31].

In light of the presented facts, it is logical to ask whether NPs (IONPs) based on compounds of the biogenic element, which is so important for vital activities, can have a bactericidal effect. On the one hand, a negative answer is expected; however, several studies noticed the antimicrobial action of IONPs [32,33]. On the other hand, the bactericidal action was repeatedly confirmed for NPs based on other biogenic elements: $\mathrm{ZnO}$ and $\mathrm{CuO}$, as was mentioned above.

Iron is like a double-edged sword. Despite its above-mentioned functions in living organisms, it is able to catalyze reactions of damaging DNA, lipids, and proteins by the Fenton reaction [34]. In this reaction, the free $\mathrm{Fe}^{2+}$ ion reacts with hydrogen peroxide $\left(\mathrm{H}_{2} \mathrm{O}_{2}\right)$; as a result, a hydroxyl radical and $\mathrm{Fe}^{3+}$ ion are formed. The following reaction of $\mathrm{Fe}^{3+}$ with the superoxide anion radical $\left(\mathrm{O}_{2}^{-\cdot}\right)$ leads to the formation of molecular oxygen $\left(\mathrm{O}_{2}\right)$ and regeneration of $\mathrm{Fe}^{2+}$ as the initial catalyst. To protect it from the damage caused by the generation of hydroxyl radicals, it is necessary to maintain an extremely low level of free iron ions inside cells [35]. ROS generation is no single mechanism of antibacterial action of IONPs. A more detail description of these mechanisms is contained in Section 2.2.

The antibacterial properties are found both in nanoparticles based on iron oxides (IONPs) and in free iron ions; however, contrary to free ions, IONPs do not exert a significant toxic effect on mammalian cells $[8,36,37]$. Iron oxide nanoparticles can be obtained by different methods, from laser ablation to chemical synthesis [38-43]. It is assumed that the antibacterial properties of iron oxide nanoparticles are associated not only with the oxide form but, also, with the size, morphology, and other physicochemical properties of nanoparticles. Several types of iron oxides are known. The most frequently found are hematite $\mathrm{Fe}_{2} \mathrm{O}_{3}$, magnetite $\mathrm{Fe}_{3} \mathrm{O}_{4}$, and limonite $\mathrm{Fe}_{2} \mathrm{O}_{3} \times \mathrm{H}_{2} \mathrm{O}[5,16]$.

Iron oxide nanoparticles (IONPs) have found wide applications in different fields of biomedicine-for example, in visualization and diagnostics [44]; in magnetic resonance imaging and computed tomography [45-48]; in positron emission tomography [49]; in cancer therapy with magnetic hyperthermia [50-52]; and for the separation of cells or molecules and the development of biosensors, which can applied to immunoassays, neuroelectronic studies, and biomedical imaging [53-56]. IONPs may be used in the imaging and tracking of brain cells in vivo [57]. A possibility of using iron oxide nanoparticles for delivering medicines and viral vectors to target cells is shown [58,59]. The antibacterial activity of iron oxide nanoparticles (IONPs) is of special interest, as the emergence of antibiotic-resistant strains is a serious problem for world public health. The direct bactericidal action of IONPs was described by the example of S. aureus [32]. $\mathrm{Fe}_{3} \mathrm{O}_{4} \mathrm{NPs}$ can be used in regenerative medicine [60]. With that, IONPs have good biocompatibility in vivo and in vitro [61,62], which qualitatively distinguish IONPs from ZnO NPs having high cytotoxicity $[63,64]$. The balance of the antimicrobial activity and biocompatibility makes IONPs an attractive candidate for the role of an antimicrobial preparation of the new generation. The present review is intended to inform readers about available data on the antibacterial properties of IONPs, a range of susceptible bacteria, mechanisms of the antibacterial action, the dependence of the antibacterial action of IONPs on the method for synthesis, and the biocompatibility of IONPs with eukaryotic cells and tissues.

\section{Main Part}

\subsection{Susceptible Microorganisms}

A list of microorganisms susceptible to the toxic action of IONPs is presented in Table 1. A minimum of 10 species of Gram-negative and 11 species of Gram-positive bacteria, as well as three fungal species susceptible to IONPs, have been mentioned in the 
literature (Table 1). The majority of the indicated microorganisms have epidemiological significance [65]. A range of the bacteriostatic concentrations for IONPs is quite wide and makes up $25-2000 \mu \mathrm{g} / \mathrm{mL}$.

Table 1. List of the microorganisms susceptible to the toxic action of IONPs.

\begin{tabular}{|c|c|c|}
\hline Group of Microorganism & Species/Serotype & Reference \\
\hline \multirow{10}{*}{ Gram-negative bacteria } & Escherichia coli & {$[33,66-80]$} \\
\hline & Klebsiella pneumoniae & {$[70,72,74,77,80-82]$} \\
\hline & Klebsiella sp. & [36] \\
\hline & Proteus mirabilis & [73] \\
\hline & Proteus vulgaris & [83] \\
\hline & Pseudomonas aeruginosa & {$[71,79,80,82,84-86]$} \\
\hline & Salmonella enterica serotype & {$[76,81,87]$} \\
\hline & Serratia marcescens & {$[32,71]$} \\
\hline & Vibrio cholerae & [8] \\
\hline & Xanthomonas sp. & [83] \\
\hline \multirow{11}{*}{ Gram-positive bacteria } & Bacillus brevis & [8] \\
\hline & Bacillus cereus & [87] \\
\hline & Bacillus licheniformis & [8] \\
\hline & Bacillus sp. & [36] \\
\hline & Bacillus subtilis & {$[8,70,72,73,76,78,79]$} \\
\hline & Corynebacterium sp. & [75] \\
\hline & Enterococcus hirae & [66] \\
\hline & Listeria monocytogenes & {$[71,87]$} \\
\hline & Micrococcus luteus & {$[67]$} \\
\hline & Staphylococcus aureus & $\begin{array}{c}{[8,33,36,67-70,72,74,76,77,79-} \\
81,85,86]\end{array}$ \\
\hline & $\begin{array}{c}\text { Staphylococcus } \\
\text { epidermidisStreptococcus mutans }\end{array}$ & {$[8,88,89]$} \\
\hline \multirow{6}{*}{ Fungi } & Aspergillus niger & [90] \\
\hline & Candida albicans & {$[87,90]$} \\
\hline & Candida glabrata & [87] \\
\hline & Candida glochares & [87] \\
\hline & Candida saitoana & [87] \\
\hline & Fusarium solani & [90] \\
\hline
\end{tabular}

IONPs have antimicrobial activity against both Gram-positive (including Staphylococcus aureus) and Gram-negative (including Escherichia coli) bacteria [33]. The data about the dependence of the antibacterial action of IONPs on the bacterial group (Gram-positive or Gram-negative) are ambiguous. On the one hand, there are data about the comparable effects of IONPs against Gram-negative and Gram-positive bacteria [91], similar to $\mathrm{CuO}$ [92], which distinguishes IONPs from $\mathrm{ZnO} N P s$ [93]. On the other hand, there are data about the more pronounced bacteriostatic action of $\mathrm{Fe}_{3} \mathrm{O}_{4}$ against Gram-negative bacteria compared to Gram-positive [66]. The authors linked the indicated differences with the peculiarities of the cell wall structure and metabolism of Gram-positive and Gram-negative bacteria [66].

\subsection{The Mechanisms of Antibacterial IONP Activity}

One of the main mechanisms of IONP toxicity is ROS generation [5,94], including in photocatalysis, Fenton reactions, or similar ones [88]. ROS, in turn, have a genotoxic action, damaging DNA molecules (Figure 1) [94]. An increase in ROS concentration can be caused by a decrease in the activity of antioxidant system enzymes (SOD, catalase, and glutathione reductase) [67]. Metal ions are able to bind mecapto $(-\mathrm{SH})$, amino $(-\mathrm{NH})$, and carboxyl (-COOH) groups of proteins, including enzymes, which leads to inactivation or partial inhibition [95]. Additionally, IONPs damage the bacterial cell wall integrity, as shown in reference [94]. The direct binding of IONPs with the cell wall of Staphylococcus 
aureus was shown by scanning electron microscopy [96]. IONPs can cause a decrease in the expression of antibiotic resistance genes (ARGs) in antibiotic-resistant bacteria found in operating rooms [5]. IONPs are able to disturb the function of $F_{0} / F_{1}-A T P a s e$ and reduce the rate of $\mathrm{H}^{+}$flow through the membrane and the redox potential [66]. The mechanisms of the antimicrobial action for IONPs have been suggested in several studies based on their size and are common for other types of metal oxide nanoparticles [95,97]. An ability to inhibit DNA replication by the inactivation of topoisomerase is described for nanoparticles with small sizes [98]. It was shown by the method of electron microscopy that $\mathrm{Fe}_{2} \mathrm{O}_{3} \mathrm{NPs}$ can bind directly with the cell wall of E. coli. IONPs can also penetrate into the cytoplasm, concentrate in it, and cause vacuole formation and cell wall disruption [84,99].

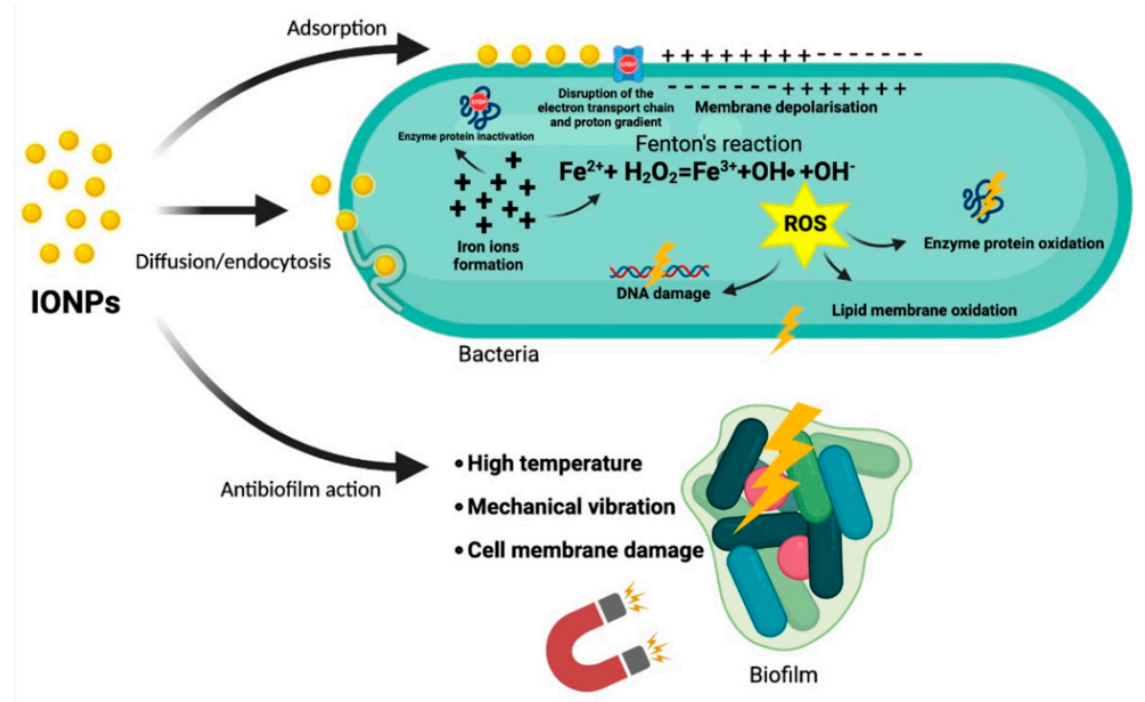

Figure 1. The mechanisms of IONP antibacterial activity.

$\mathrm{Fe}_{3} \mathrm{O}_{4}$ IONPs can concentrate between the outer and inner membranes of the cell wall in Gram-negative bacteria due to binding with the FHL complex in the inner membrane. Therefore, $\mathrm{Fe}_{3} \mathrm{O}_{4}$ IONPs have more pronounced antimicrobial actions against Gram-negative bacteria [66].

Bactericidal and antibiofilm activities were shown in $\mathrm{Fe}_{3} \mathrm{O}_{4} \mathrm{IONPs}$. Positively charged and neutral IONPs promoted a higher reduction of Streptococcus mutans biofilms compared with negatively charged IONPs [89]. IONPs coated with oleic acid can prevent biofilm formation by S. aureus and P. aeruginosa [85]. IOPNs have the ability to adsorb and penetrate into bacterial biofilms due to their physicochemical characteristics, such as a surface charge, hydrophobicity, and high surface area ratio by volume [100,101].

Iron oxide nanoparticles have both magnetic and paramagnetic properties [68,87,102]. $\mathrm{Fe}_{3} \mathrm{O}_{4}$ NPs with high paramagnetic activity are also named superparamagnetic iron oxide nanoparticles (SPIONs) $[103,104]$. SPIONs in the presence of the alternating magnetic fields cause cell death and biofilm destruction due to the vibration damage, local hyperthermia, and ROS generation. All of the above-mentioned factors lead to the dissociation of bacteria from a biofilm, damage of the bacterial cell wall, membrane rupture, the fusion of different cells with each other, and death [69].

In $80 \%$ of studies, IONPs show only bacteriostatic action. The bactericidal action of IONPs is described in the literature in $20 \%$ of cases.

\subsection{Methods of IOPNs Synthesis}

The methods for IONP synthesis are multiple and include coprecipitation [105], thermal decomposition [70], low temperature synthesis [71], the sol-gel method [106], hydrothermal method [69], electrochemical method [83], laser ablation [91,107], sonochemical, microwave, microemulsion methods, matrix-mediated method using PVA, "green synthe- 
sis" [68], and many others [32,84,108]. In the case of research of IONP antibacterial effects, most used in coprecipitation, thermal decomposition, the sol-gel method, laser ablation, and "green synthesis" (Table 2); therefore, we shall briefly describe these methods below.

Aqueous coprecipitation is the most widely used chemical method of IONP synthesis $[105,109]$. In this method, IOPNs are synthesized by the simultaneous precipitation of $\mathrm{Fe}^{2+}$ and $\mathrm{Fe}^{3+}$ salts (molar ratio 1:2) in a basic solution at room temperature or under heat $[105,109,110]$. The advantage of the coprecipitation method is the low cost of IOPNs synthesis. It is important in cases of large-scale production [27]. The disadvantages of the method are the large size distribution of produced IONPs, aggregation, poor crystallinity, a high possibility of oxidation, and poor magnetic property [111]. The change of $\mathrm{pH}$ in the solution can improve the properties of IONPs synthesized by coprecipitation [112].

The thermal decomposition is a nonaqueous synthesis in which organometallic compounds such as $\mathrm{Fe}(\mathrm{Acac})_{3}, \mathrm{Fe}\left(\mathrm{C}_{2} \mathrm{O}_{4}\right) \times 2 \mathrm{H}_{2} \mathrm{O}, \mathrm{Fe}\left(\mathrm{CH}_{3} \mathrm{COO}\right)_{2}$, or ferrocene suffer decay at high temperatures in organic solvents (high boiled) or via being solvent-free in the presence of stabilizing surfactants like aliphatic amine and fatty acids [113]. This method may generate high-quality IONPs with close distributions of particle sizes and a high magnetism and degree of crystallinity [113]. Addition advantages of this method are the high yield and absence of IONP aggregation [114]. The main disadvantage of this method is the insolubility of produced IONPs in water. Therefore, further steps are required to make their surfaces hydrophilic and use IONPs in biological solutions [115].

The sol-gel method (wet-chemical method) is a sum of reactions of condensation and hydrolysis between iron alkoxides and salts (e.g., chlorides, nitrates, and acetates) [116]. The main advantage of this method is a good homogeneity and size and high purity and quantity of IONPs [116]. The disadvantages of the method are the requirements for compliance with exact values of the $\mathrm{pH}$, temperature, and concentration of the reagents during a synthesis; high cost of precursors; and low wear resistance of synthesized IONPs [117].

Laser ablation synthesis in a solution is a synthesis that is triggered by the immersion of pulsed laser beams on the target material in a liquid solution [118]. Laser ablation synthesis allows to work with a wide range of materials and solvents. The size and clustering of IONPs are difficult to control [118]. Laser ablation allows the synthesis of FeOx crystal to a few atom clusters in the following modification: phosphonates as an aqueous solution and bulk iron as a target [72].

The so-called "green synthesis" has aroused considerable interest. It is a modification of synthesis methods (as a rule, coprecipitation) with the application of plant extracts used as a reducing agent. There are reports about the application of leaf extracts of the Psidium guajava [68], Cynometra ramiflora [88], Sida cordifolia [119], Zea mays [87], Argemone mexicana [73], Couroupita guianensis [81], Tridax procumb [120], peel extracts of Punica granatum [70], Ruellia tuberosa [74], Malva sylvestris [82], and Citrus sinensis [121]. This method is low-cost, if coprecipitation is used as a basic technique [74,82,121].

Large-scale synthesis is a modification of the coprecipitation method with controlled heating and addition polyacrilic acid salts or sodium oleate as the surfactant [103]

The hydrothermal method is a synthesis of IONPs from iron precursors at high pressure and temperature conditions in an aqueous medium [103,104]. Aqueous synthesis methods generate particles with low crystallization [122]. Replacing water with other organic solvents allows the formation of IONPs with high crystallinity and controlled shapes. This method is named solvothermal synthesis [113]. The disadvantage of this method is the long time it takes for synthesis (hours to days) [123].

\subsection{Dependence of the Antimicrobial Action of IONPs on the Size and Type of Iron Oxides}

The majority of studied IONPs have a spherical shape (Table 2), which excludes a contribution of the shape into the antimicrobial action. Therefore, we assessed the sizes and compositions of IONPs. Based on the analyzed literature data, we did not reveal an association between the IONPs' size and the minimum bacteriostatic concentrations (Figure 2a). Several IONP types are distinguished depending on the oxide on which 
basis they are synthesized: NPs based on hematite $\left(\alpha-\mathrm{Fe}_{2} \mathrm{O}_{3}\right)[5,68], \beta-\mathrm{Fe}_{2} \mathrm{O}_{3}, \gamma-\mathrm{Fe}_{2} \mathrm{O}_{3}$, $\varepsilon-\mathrm{Fe}_{2} \mathrm{O}_{3}$ [124-126], and $\mathrm{Fe}_{3} \mathrm{O}_{4}[83,127]$. We found that $\mathrm{Fe}_{2} \mathrm{O}_{3}$ NPs show more pronounced bacteriostatic actions compared to $\mathrm{Fe}_{3} \mathrm{O}_{4} \mathrm{NPs}$ (Figure $2 \mathrm{~b}$ ). For more detailed analyses, we assessed the contribution of a method for IONP synthesis of their antimicrobial properties.

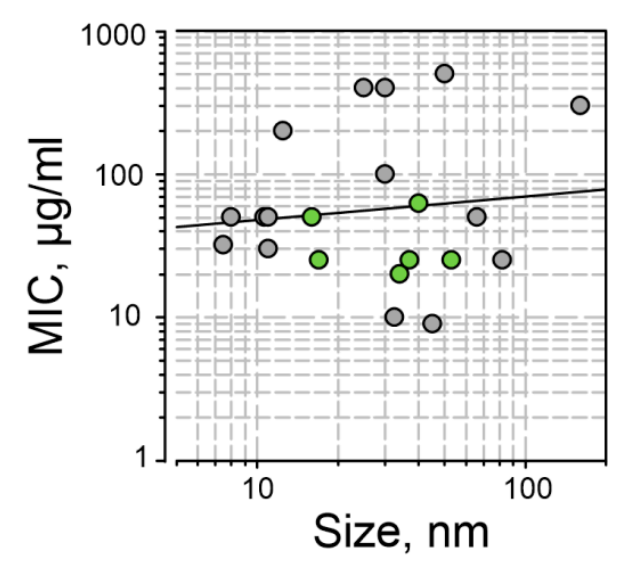

(a)

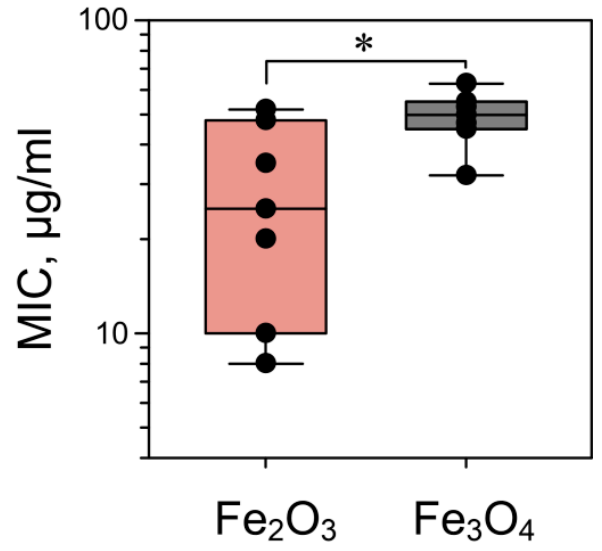

(b)

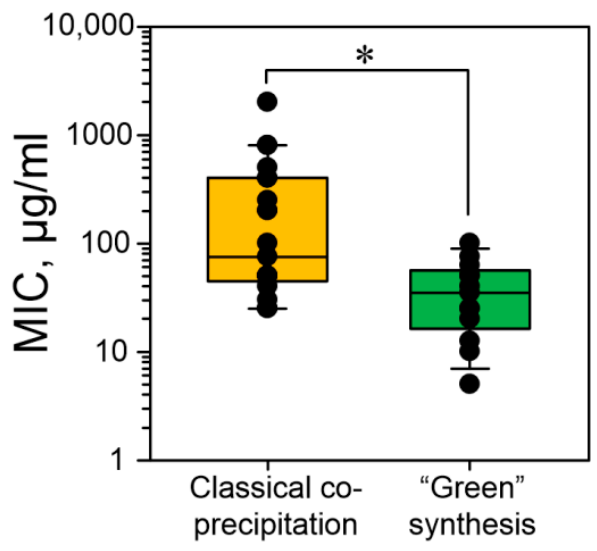

(c)

Figure 2. (a) Assessment of the dependence of the IONP MIC against E. coli on the IONP size. (b) Assessment of the dependence of the IONP MIC against E. coli on the iron oxide type. (c) Assessment of the dependence of the IONP MIC against $E$. coli in the synthesis method. Values of the minimum inhibitory concentrations are taken from the sources in Table 2. In (a), the grey color shows the values for the IONPs obtained without "green synthesis", and the green color shows the values for the IONPs obtained by "green synthesis". * $-p<0.05$ by the Mann-Whitney $U$ test.

\subsection{Dependence of the Antimicrobial Action of IONPs on a Synthesis Method}

The methods for IONPs synthesis are multiple and include coprecipitation [105], thermal decomposition [70], low-temperature synthesis [71], the sol-gel method [106], hydrothermal method [69], electrochemical method [83], laser ablation [91,107], sonochemical, microwave, microemulsion methods, matrix-mediated method using PVA, and many others $[32,84,108]$. IONPs synthesized by the low-temperature method from iron sulfate showed an antimicrobial effect against E. coli, P. aeruginosa, Serratia marcescens, and Listeria monocytogenes, exerting bacteriostatic action and inhibiting biofilm formation [71]. NPs obtained by laser ablation had comparable bacteriostatic effects against Gram-negative (Escherichia coli, Pseudomonas aeruginosa, and Serratia marcescens) and Gram-positive (Staphylococcus aureus) bacteria. The bacteriostatic actions of IONPs do not depend on a solvent (SDS or DMF) or bacterial group (Gram-positive or Gram-negative) [91].

\subsubsection{Coprecipitation Method}

The most common method for IONP synthesis when studying the antimicrobial properties is the coprecipitation of salts $\mathrm{Fe}^{3+} / \mathrm{Fe}^{2+}[56,73,75,86,127-129]$. This synthesis method is the most available. Modifications of the method are possible. For instance, the addition of oleic acid for the generation of conjugated IONPs [127,129], as well as the coprecipitation of different metal salts, allow us to obtain composite NPs-for example, based on $\mathrm{FeSO}_{4} \times 7 \mathrm{H}_{2} \mathrm{O}$ and $\mathrm{Co}\left(\mathrm{NO}_{3}\right)_{2} \times 6 \mathrm{H}_{2} \mathrm{O}$ [76]. One of the methods for improving the antimicrobial properties of IONPs is the use of composites-for example, $\alpha-\mathrm{Fe}_{2} \mathrm{O}_{3} / \mathrm{Co}_{3} \mathrm{O}_{4}$ [105]. Composite NPs have more pronounced antimicrobial actions against B. subtilis, S. aureus, E.coli, and S. typhimirium. The synergistic effect of $\mathrm{Fe}_{2} \mathrm{O}_{3}$ and $\mathrm{Co}_{3} \mathrm{O}_{4}$ was observed compared to oxides used individually. However, upon the strong bacteriostatic action (practically a full inhibition of the bacterial growth at a concentration of $1200 \mathrm{mg} / \mathrm{mL}$ ), the bactericidal action was almost absent [76]. $\alpha-\mathrm{Fe}_{2} \mathrm{O}_{3} / \mathrm{ZnO}$ NPs show more pronounced bacteriostatic actions against Gram-positive Bacillus subtilis and Staphylococcus aureus and 
Gram-negative Escherichia coli and Salmonella typhi than IONPs and ZnO NPs; with that, the size of the inhibition zone increases when the $\mathrm{ZnO}$ concentration in the composite is increased [76], (Table 2).

Compared to $\mathrm{Fe}_{3} \mathrm{O}_{4} \mathrm{NPs}$, the composite $\mathrm{Fe}_{3} \mathrm{O}_{4} / \mathrm{SiO}_{2} \mathrm{NPs}$ has a more pronounced photocatalytic bactericidal action against Escherichia coli and Staphylococcus aureus; with that, the effect was higher against Gram-positive bacteria [130]. The use of the combined method for IONPs synthesis allows achieving a significant bacteriostatic effect against Staphylococcus aureus, Xanthomonas, Escherichia coli, and Proteus vulgaris [83].

\subsection{2. "Green Synthesis"}

The so-called "green synthesis" has aroused considerable interest. It is a modification of synthesis methods (as a rule, coprecipitation) with the application of plant extracts used as a reducing agent $[83,106-110]$.

IONPs synthetized by the "green" method show comparable antimicrobial effects against both Gram-negative (E. coli) and Gram-positive (S. aureus) bacteria [68]. However, the antimicrobial effect of $50-100 \mu \mathrm{g} / \mu \mathrm{L}$ of IONPs is about three times lower than that of $20 \mu \mathrm{g} / \mathrm{mL}$ of streptomycin. IONPs synthesized in the presence of Punica granatum peel extract exert a bacteriostatic effect on Pseudomonas aeruginosa; with that, these IONPs do not have hemolytic activity against erythrocytes [70]. IONPs in complex with Cynometra ramiflora extract have more pronounced bacteriostatic effects against Gram-positive $S$. epidermalis compared to Gram-negative E. coli [88]. NPs synthesized in the medium of the Zea mays extract did not have their own antimicrobial and antifungal properties but significantly enhanced the bacteriostatic action of kanamycin and rifampicin against Grampositive Bacillus cereus, Listeria monocytogenes, and Staphylococcus aureus and Gram-negative Escherichia coli and Salmonella typhimurium, as well as the antifungal activity these antibiotics against six strains of Candida [87]. In addition to the antimicrobial properties, IONPs obtained as a result of "green" synthesis had antioxidant properties and inhibited their proteasome activity, which allowed us to regard IONPs as possible candidates for cancer therapy [87].

Compared to $\mathrm{Fe}_{3} \mathrm{O}_{4} \mathrm{NPs}, \mathrm{Fe}_{3} \mathrm{O}_{4} /$ Malva sylvestris NPs had more pronounced bacteriostatic and bactericidal effects against Staphylococcus aureus, Corynebacterium sp., Pseudomonas aeruginosa, and Klebsiella pneumoniae and exerted cytotoxic action against the Hep-G2 and MCF-7 cell lines [82].

IONPs synthesized in the Argemone mexicana extract had more pronounced bacteriostatic activity against E. coli, P. mirabilis, and B. subtilis than pure IONPs, which was comparable with the effects of streptomycin [73]. 
Table 2. Parameters of the nanoparticles reported in the literature.

\begin{tabular}{|c|c|c|c|c|c|c|c|c|c|}
\hline № & Synthesis Method & Composition & Size, $\mathrm{nm}$ & Shape & Concentration & $\begin{array}{c}\text { Medium, } \\
\text { Conditions }\end{array}$ & Microorganism & $\begin{array}{c}\text { Biological } \\
\text { Effect }\end{array}$ & Ref \\
\hline 1 & Coprecipitation method & $\mathrm{Fe}_{2} \mathrm{O}_{3}$ & $25-40$ & Sph & $10-50 \mu \mathrm{g} / \mathrm{mL}$ & $\mathrm{NA}, 48 \mathrm{~h}, 37^{\circ} \mathrm{C}$ & $\begin{array}{c}\text { E. coli, } \\
\text { S. aureus, } \\
\text { S. dysentery } \\
\end{array}$ & BS & [33] \\
\hline 2 & $\begin{array}{c}\text { Chemical precipitation using } \\
\text { Psidium Guajava leaf extract } \\
\text { as a reducing agent followed } \\
\text { by heat treatment }\end{array}$ & $\mathrm{Fe}_{2} \mathrm{O}_{3}$ & 34 & Sph & $20-100 \mu \mathrm{g} / \mathrm{mL}$ & MHA, $24 \mathrm{~h}, 37^{\circ} \mathrm{C}$ & $\begin{array}{l}\text { E. coli, } \\
\text { S. aureus }\end{array}$ & BS & [68] \\
\hline 3 & $\begin{array}{c}\text { Chemical precipitation using } \\
\text { Punica granatum peel extract } \\
\text { as a reducing agent followed } \\
\text { by heat treatment }\end{array}$ & - & - & - & $31 \mu \mathrm{g} / \mathrm{mL}$ & $\mathrm{MHA}, 24 \mathrm{~h}, 37^{\circ} \mathrm{C}$ & P. aeruginosa & BS & [70] \\
\hline 4 & Wet chemical method & $\mathrm{Fe}_{3} \mathrm{O}_{4}$ & $33-40$ & Sph & $25-100 \mu \mathrm{g} / \mathrm{mL}$ & $\mathrm{NA}, 24 \mathrm{~h}, 37^{\circ} \mathrm{C}$ & $\begin{array}{c}\text { E. coli, } \\
\text { P. vulgaris, } \\
\text { S. aureus, } \\
\text { Xanthomonas sp. }\end{array}$ & BS & [83] \\
\hline 6 & Coprecipitation & $\begin{array}{c}\alpha-\mathrm{Fe}_{2} \mathrm{O}_{3} / \mathrm{Co}_{3} \mathrm{O}_{4} \\
\text { composite }\end{array}$ & 25 & $\begin{array}{l}\text { Rod/ } \\
\text { hexag }\end{array}$ & $400-800 \mu \mathrm{g} / \mathrm{mL}$ & $\mathrm{MHA}, 24 \mathrm{~h}, 37^{\circ} \mathrm{C}$ & $\begin{array}{c}\text { B. subtilis, } \\
\text { E. coli, } \\
\text { S. aureus, } \\
\text { S. typhimurium. }\end{array}$ & $\mathrm{BC}$ & [76] \\
\hline 7 & $\begin{array}{c}\text { Chemical precipitation using } \\
\text { Cynometra ramiflora extract as } \\
\text { a reducing agent }\end{array}$ & $\mathrm{Fe}_{2} \mathrm{O}_{3} / \mathrm{Fe}_{3} \mathrm{O}_{4}$ & - & Sph & $\begin{array}{c}70 \mu \mathrm{L} \text { of IONPs } \\
\text { suspen- } \\
\text { sion/disk }\end{array}$ & $\mathrm{NA}, 24 \mathrm{~h}, 37^{\circ} \mathrm{C}$ & $\begin{array}{c}\text { E.coli, } \\
\text { S. epidermidis }\end{array}$ & BS & [88] \\
\hline 8 & Coprecipitation method & $\begin{array}{c}\alpha-\mathrm{Fe}_{2} \mathrm{O}_{3} \\
\mathrm{ZnO} / \alpha-\mathrm{Fe}_{2} \mathrm{O}_{3}\end{array}$ & $\sim 30$ & Sph/oval & $400-800 \mu \mathrm{g}$ & $\mathrm{MHA}, 24 \mathrm{~h}, 37^{\circ} \mathrm{C}$ & $\begin{array}{c}\text { B. subtilis, } \\
\text { E. coli, } \\
\text { S. aureus, } \\
\text { S. typhimurium }\end{array}$ & BS & [76] \\
\hline
\end{tabular}


Table 2. Cont.

\begin{tabular}{|c|c|c|c|c|c|c|c|c|c|}
\hline № & Synthesis Method & Composition & Size, $\mathrm{nm}$ & Shape & Concentration & $\begin{array}{l}\text { Medium, } \\
\text { Conditions }\end{array}$ & Microorganism & $\begin{array}{l}\text { Biological } \\
\text { Effect }\end{array}$ & Ref \\
\hline 9 & Coprecipitation method & $\mathrm{Fe}_{3} \mathrm{O}_{4}$ & $6-9$ & Sph & $32-128 \mu \mathrm{g} / \mathrm{mL}$ & LB broth, $37^{\circ} \mathrm{C}$ & $\begin{array}{l}\text { E. coli, } \\
\text { L. monocytogenes, } \\
\text { P. aeruginosa, } \\
\text { S. marcescens }\end{array}$ & BS & [71] \\
\hline 10 & $\begin{array}{l}\text { Chemical precipitation using } \\
\text { Sida cordifolia as a reducing } \\
\text { agent and stabilizer }\end{array}$ & $\mathrm{Fe}_{2} \mathrm{O}_{3}$ & 16 & Sph & $50 \mu \mathrm{g} / \mathrm{mL}$ & MHA, $24 \mathrm{~h}, 37^{\circ} \mathrm{C}$ & $\begin{array}{l}\text { B. subtilis, } \\
\text { E. coli, } \\
\text { K. pneumoniae, } \\
\text { S. aureus }\end{array}$ & BS & [119] \\
\hline 11 & Coprecipitation method & $\begin{array}{l}\text { IONPs with } \\
\text { amoxicillin }\end{array}$ & - & - & $0.05-10 \mathrm{mM}$ & $\mathrm{TSB}, 24 \mathrm{~h}, 37^{\circ} \mathrm{C}$ & $\begin{array}{l}\text { P. aeruginosa, } \\
\text { S. aureus }\end{array}$ & $\begin{array}{l}\text { Stimulation of } \\
\text { bacterial growth } \\
\text { in the presence } \\
\text { of humic acid }\end{array}$ & [86] \\
\hline 12 & $\begin{array}{l}\text { Ready commercial product } \\
\text { (Sigma-Aldrich) }\end{array}$ & $\mathrm{Fe}_{2} \mathrm{O}_{3}$ & $<5$ & - & $0.05-10 \mathrm{mM}$ & $\mathrm{LB}, 37^{\circ} \mathrm{C}$ & E. coli & $\mathrm{BC}$ & [99] \\
\hline 14 & $\begin{array}{l}\text { Coprecipitation method in } \\
\text { alkaline media with leaf } \\
\text { extract of } A \text {. mexicana }\end{array}$ & $\mathrm{Fe}_{3} \mathrm{O}_{4}$ & $10-30$ & Sph & $12.5-50 \mathrm{mg} /$ disc & $\mathrm{MHB}, 24 \mathrm{~h}, 37^{\circ} \mathrm{C}$ & $\begin{array}{l}\text { B. subtilis, } \\
\text { E. coli, } \\
\text { P. mirabilis, }\end{array}$ & BS & [73] \\
\hline 15 & $\begin{array}{c}\text { Laser ablation in } \\
\text { dimethylformamide (DMF) } \\
\text { and sodium dodecyl sulfate } \\
\text { (SDS) solutions }\end{array}$ & $\alpha-\mathrm{Fe}_{2} \mathrm{O}_{3}$ & $50-110$ & Sph & $4.25 \mathrm{mg} / \mathrm{mL}$ & $\mathrm{NA}, 24 \mathrm{~h}, 37^{\circ} \mathrm{C}$ & $\begin{array}{l}\text { E. coli, } \\
\text { P. aeruginosa, } \\
\text { S. aureus, } \\
\text { S. marcescens }\end{array}$ & BS & [91] \\
\hline
\end{tabular}


Table 2. Cont.

\begin{tabular}{|c|c|c|c|c|c|c|c|c|c|}
\hline № & Synthesis Method & Composition & Size, nm & Shape & Concentration & $\begin{array}{l}\text { Medium, } \\
\text { Conditions }\end{array}$ & Microorganism & $\begin{array}{c}\text { Biological } \\
\text { Effect }\end{array}$ & Ref \\
\hline 16 & $\begin{array}{c}\text { Coprecipitation using } \\
\text { Couroupita guianensis aqueous } \\
\text { fruit extract }\end{array}$ & $\mathrm{Fe}_{3} \mathrm{O}_{4}$ & $\sim 17$ & Sph & $25-75 \mu \mathrm{g} / \mathrm{mL}$ & $\mathrm{NA}, 24 \mathrm{~h}, 37^{\circ} \mathrm{C}$ & $\begin{array}{c}\text { E. coli, } \\
\text { K. pneumoniae, } \\
\text { S. typhimurium }\end{array}$ & BS & [81] \\
\hline 17 & Coprecipitation & $\begin{array}{c}\mathrm{Fe}_{3} \mathrm{O}_{4} \text { coated by } \\
\mathrm{SiO}_{2}\end{array}$ & $\sim 20$ & Sph & - & $\mathrm{NA}, 24 \mathrm{~h}, 37^{\circ} \mathrm{C}$ & $\begin{array}{l}\text { E. coli, } \\
\text { S. aureus, }\end{array}$ & BS & [130] \\
\hline 18 & $\begin{array}{c}\text { Chemical precipitation using } \\
\text { Tridax procumbens leaf extract } \\
\text { as a reducing agent }\end{array}$ & $\mathrm{Fe}_{3} \mathrm{O}_{4}$ & - & Sph & $10-40 \mu \mathrm{L}$ & PDA & P. aeruginosa & BS & [120] \\
\hline 19 & Coprecipitation & $\mathrm{Fe}_{3} \mathrm{O}_{4}$ & 8 & Sph & $50-200 \mu \mathrm{g} / \mathrm{mL}$ & $\mathrm{LB}, 37^{\circ} \mathrm{C}, 14 \mathrm{~h}$ & E. coli & BS & [75] \\
\hline 20 & Ultra-large-scale synthesis & $\begin{array}{c}\mathrm{Fe}_{3} \mathrm{O}_{4} \text { or } \\
\mathrm{Fe}_{3} \mathrm{O}_{4} \text { coated by } \\
\text { alginate } \\
\end{array}$ & $\begin{array}{l}\sim 16, \text { for coated } \\
\text { with alginate } \\
\sim 230 \\
\end{array}$ & Sph & $2.5-10 \mu \mathrm{g}$ & $\mathrm{LB}, 37^{\circ} \mathrm{C}, 16-18 \mathrm{~h}$ & P. aeruginosa & BS & [95] \\
\hline 21 & $\begin{array}{l}\text { Chemical precipitation using } \\
\text { Ruellia tuberosa leaf aqueous } \\
\text { extract as a reducing agent }\end{array}$ & $\mathrm{FeO}$ & 52.78 & Rod & $25-75 \mu \mathrm{g} / \mathrm{mL}$ & MHA, $24 \mathrm{~h}, 37^{\circ} \mathrm{C}$, & $\begin{array}{l}\text { E. coli, } \\
\text { K. pneumoniae, } \\
\text { S. aureus }\end{array}$ & BS & [74] \\
\hline 23 & $\begin{array}{l}\text { Coprecipitation using Malva } \\
\text { sylvestris as a reducing agent }\end{array}$ & $\mathrm{Fe}_{3} \mathrm{O}_{4}$ & $30-50$ & Sph & $62.5 \mathrm{mg} / \mathrm{mL}$ & $\mathrm{BHI}, 24 \mathrm{~h}, 37^{\circ} \mathrm{C}$ & $\begin{array}{c}\text { Corynebacterium } \\
\text { sp., } \\
\text { K. pneumonia, } \\
\text { P. aeruginosa, } \\
\text { S. aureus, }\end{array}$ & $\mathrm{BS}, \mathrm{BC}$ & {$[82]$} \\
\hline 24 & $\begin{array}{l}\text { One-pot hydrothermal } \\
\text { method }\end{array}$ & $\mathrm{Fe}_{3} \mathrm{O}_{4}$ & $\sim 160$ & Sph & $\begin{array}{c}300-1000 \\
\mu \mathrm{g} / \mathrm{mL}\end{array}$ & $\mathrm{LB}, 37^{\circ} \mathrm{C}, 14 \mathrm{~h}$ & $\begin{array}{l}\text { E. coli, } \\
\text { S. aureus }\end{array}$ & BS & [69] \\
\hline 25 & $\begin{array}{c}\text { Chemical precipitation using } \\
\text { orange peel extract as a } \\
\text { reducing and stabilizing } \\
\text { agent }\end{array}$ & $\mathrm{Fe}_{2} \mathrm{O}_{3}$ & $\sim 50$ & - & $0.5 \mathrm{mg} / \mathrm{mL}$ & $\mathrm{NA}, 36^{\circ} \mathrm{C}, 24 \mathrm{~h}$ & $\begin{array}{l}\text { B. subtilis, } \\
\quad \text { E. coli, } \\
\text { P. aeruginosa, } \\
\text { S. aureus }\end{array}$ & BS & [121] \\
\hline
\end{tabular}


Table 2. Cont.

\begin{tabular}{|c|c|c|c|c|c|c|c|c|c|}
\hline № & Synthesis Method & Composition & Size, $\mathrm{nm}$ & Shape & Concentration & $\begin{array}{c}\text { Medium, } \\
\text { Conditions }\end{array}$ & Microorganism & $\begin{array}{l}\text { Biological } \\
\text { Effect }\end{array}$ & Ref \\
\hline 26 & $\begin{array}{l}\text { Chemical precipitation using } \\
\text { Urtica leaf extract as a } \\
\text { reducing agent } \\
\text { Coprecipitation }\end{array}$ & $\begin{array}{c}\alpha-\mathrm{Fe}_{2} \mathrm{O}_{3} \\
\alpha-\mathrm{Fe}_{2} \mathrm{O}_{3}-\mathrm{Ag}\end{array}$ & 100-200 & Different & $\begin{array}{c}35 \mu \mathrm{g} / \mathrm{mL} \\
5-35 \mu \mathrm{g} / \mathrm{disc}\end{array}$ & MHA, 24 h, $37^{\circ} \mathrm{C}$, & $\begin{array}{c}\text { Bacillus sp., } \\
\text { E. coli, } \\
\text { K. pneumoniae, } \\
\text { S. aureus } \\
\text { E. coli } \\
\text { DH5 } \alpha \text {-pUC18 } \\
\text { ampicillin- } \\
\text { resistant; } \\
\text { E. coli pARG-25 } \\
\text { kanamycin- } \\
\text { resistant }\end{array}$ & BS & [36] \\
\hline 28 & Coprecipitation & $\mathrm{Fe}_{3} \mathrm{O}_{4}$ & $10-120$ & Sph & $50 \mathrm{mg} / \mathrm{mL}$ & $\mathrm{NA}, 24 \mathrm{~h}, 37^{\circ} \mathrm{C}$ & $\begin{array}{c}\text { B. brevis, } \\
\text { B. licheniformis, } \\
\text { B. subtilis, } \\
\text { E. coli, } \\
\text { P. aeruginosa, } \\
\text { S. aureus, } \\
\text { S. epidermidis, } \\
\text { S. flexneri, } \\
\text { V. cholera }\end{array}$ & BS & [9] \\
\hline 29 & Coprecipitation & $\begin{array}{c}\mathrm{Fe}_{3} \mathrm{O}_{4} \\
\mathrm{Co} / \mathrm{Fe}_{2} \mathrm{O}_{4} \\
\mathrm{Mn} / \mathrm{Fe}_{2} \mathrm{O}_{4} \\
\end{array}$ & $14-68$ & Cubic spinel & $25-2000 \mu \mathrm{g} / \mathrm{mL}$ & $\mathrm{NB}, \mathrm{NA}, 24 \mathrm{~h}, 37^{\circ} \mathrm{C}$ & $\begin{array}{l}\text { B. subtilis, } \\
\text { E. coli }\end{array}$ & BS & [102] \\
\hline 30 & Solvothermal method & $\begin{array}{l}\text { IONPs modified } \\
\text { with oleic acid }\end{array}$ & 75-1110 & Sph & $25-125 \mu \mathrm{g} / \mathrm{mL}$ & $\begin{array}{c}\text { LB broth, } 48 \mathrm{~h}, 37 \\
{ }^{\circ} \mathrm{C},\end{array}$ & $\begin{array}{l}\text { P. aeruginosa, } \\
\text { S. aureus }\end{array}$ & BS & [85] \\
\hline 31 & $\begin{array}{l}\text { Laser ablation in } \\
\text { dimethylformamide (DMF) } \\
\text { and sodium dodecyl sulfate } \\
\text { (SDS) solutions }\end{array}$ & $\alpha-\mathrm{Fe}_{2} \mathrm{O}_{3}$ & $50-110$ & Sph & - & $\mathrm{NA}, 24 \mathrm{~h}, 37^{\circ} \mathrm{C}$ & $\begin{array}{l}\text { E. coli, } \\
\text { P. aeruginosa, } \\
\text { S. aureus, } \\
\text { S. marcescens }\end{array}$ & BS & [91] \\
\hline
\end{tabular}


Table 2. Cont.

\begin{tabular}{|c|c|c|c|c|c|c|c|c|c|}
\hline № & Synthesis Method & Composition & Size, $\mathrm{nm}$ & Shape & Concentration & $\begin{array}{l}\text { Medium, } \\
\text { Conditions }\end{array}$ & Microorganism & $\begin{array}{l}\text { Biological } \\
\text { Effect }\end{array}$ & Ref \\
\hline 32 & Sol-gel combustion & $\mathrm{Fe}_{2} \mathrm{O}_{3}$ & $35.16 \pm 1.47$ & Sph & $65 \pm 1.5 \mu \mathrm{g} / \mathrm{mL}$ & $\begin{array}{c}\mathrm{MHB}, 24 \mathrm{~h}, 35 \pm 2 \\
{ }^{\circ} \mathrm{C},\end{array}$ & $\begin{array}{l}\text { B. subtilis, } \\
\text { E. coli, } \\
\text { P. aeruginosa, } \\
\text { S. aureus }\end{array}$ & Low BC & [13] \\
\hline 33 & $\begin{array}{c}\text { Matrix-mediated method } \\
\text { using PVA } \\
\text { (polyvinyl acetate) }\end{array}$ & $\mathrm{Fe}_{3} \mathrm{O}_{4} / \mathrm{Fe}_{2} \mathrm{O}_{3}$ & $9 \pm 4$ & Sph & $30-3000 \mu \mathrm{g} / \mathrm{mL}$ & $\mathrm{TSB}, 24 \mathrm{~h}, 37^{\circ} \mathrm{C}$, & S. aureus & BS, BC & [32] \\
\hline 34 & Laser ablation in the water & $\begin{array}{l}\text { IONPs/carbon } \\
\text { nanotubes }\end{array}$ & $6-7$ & $\begin{array}{l}\text { Sph IO on } \\
\text { the carbon } \\
\text { nanotubes }\end{array}$ & $400-800 \mu \mathrm{g} / \mathrm{mL}$ & $\mathrm{NB}, 24 \mathrm{~h}, 37^{\circ} \mathrm{C}$, & $\begin{array}{l}\text { E. coli, } \\
\text { K. pneumoniae, } \\
\text { S. aureus }\end{array}$ & BS & [77] \\
\hline 35 & Coprecipitation & $\begin{array}{l}\mathrm{Fe}_{3} \mathrm{O}_{4} \\
\text { conjugated with } \\
\text { TEPSA or TPED }\end{array}$ & $\begin{array}{c}14.6 \pm 1.4 \\
20.4 \pm 1.3 \text { or } \\
21.2 \pm 1.6\end{array}$ & Sph & $1-3 \mu \mathrm{g} / \mathrm{mL}$ & $\begin{array}{l}\text { TYE, } 24 \mathrm{~h}, 37^{\circ} \mathrm{C} \text {, in } \\
\text { the dark }\end{array}$ & $\begin{array}{l}\text { Streptococcus } \\
\text { mutans }\end{array}$ & $\mathrm{BC}$ & [89] \\
\hline 36 & Coprecipitation & $\begin{array}{l}\mathrm{Fe}_{3} \mathrm{O}_{4} \text { coated by } \\
\text { citric acid }\end{array}$ & $\sim 30$ & Sph & $100 \mu \mathrm{g} / \mathrm{mL}$ & $\mathrm{NA}, 24 \mathrm{~h}, 37^{\circ} \mathrm{C}$ & $\begin{array}{c}\text { E. coli, } \\
\text { S. typhimurium }\end{array}$ & BS & [131] \\
\hline 38 & Coprecipitation & $\begin{array}{l}\mathrm{Fe}_{3} \mathrm{O}_{4} \text { coated by } \\
\text { chitosan }\end{array}$ & $\sim 11$ & Sph & $30-40 \mu \mathrm{g} / \mathrm{mL}$ & $\begin{array}{l}\text { TSA for bacteria, } \\
\text { YEPD for C. albicans, } \\
\text { CYA for } \\
\text { A. niger, Potato } \\
\text { sucrose agar for } F \text {. } \\
\text { solani. } \\
48 \mathrm{~h} \text { at } 30^{\circ} \mathrm{C}\end{array}$ & $\begin{array}{c}\text { A. niger, } \\
\text { B. subtilis, } \\
\text { C. albicans, } \\
\text { E. coli, } \\
\text { F. solani }\end{array}$ & BS & [90] \\
\hline 39 & Coprecipitation method & $\begin{array}{c}\mathrm{Fe}_{2} \mathrm{O}_{3}, \mathrm{FeO}, \\
\text { coated by } \\
\text { gentamicin }\end{array}$ & $10-15$ & Sph & $200 \mu \mathrm{g} / \mathrm{mL}$ & $\begin{array}{c}\text { LB broth, } 24 \mathrm{~h}, 37 \\
{ }^{\circ} \mathrm{C}\end{array}$ & $\begin{array}{l}\text { B. subtilis, } \\
\text { E. coli, } \\
\text { P. aeruginosa, } \\
\text { S. aureus }\end{array}$ & $\mathrm{BC}$ & [79] \\
\hline 40 & Coprecipitation & $\mathrm{Fe}_{3} \mathrm{O}_{4}$ & $20-25$ & - & $5-80 \mu \mathrm{g} / \mathrm{mL}$ & $\mathrm{NB}, 24 \mathrm{~h}, 37^{\circ} \mathrm{C}$ & $\begin{array}{c}\text { B. cereus, } \\
\text { K. pneumoniae, }\end{array}$ & $\mathrm{BS}, \mathrm{BC}$ & [132] \\
\hline
\end{tabular}


Table 2. Cont.

\begin{tabular}{|c|c|c|c|c|c|c|c|c|c|}
\hline № & Synthesis Method & Composition & Size, nm & Shape & Concentration & $\begin{array}{c}\text { Medium, } \\
\text { Conditions }\end{array}$ & Microorganism & $\begin{array}{c}\text { Biological } \\
\text { Effect }\end{array}$ & Ref \\
\hline 41 & $\begin{array}{l}\text { Coprecipitation using } \\
\text { Glycosmis } \\
\text { mauritiana water extract as a } \\
\text { reducing agent }\end{array}$ & $\mathrm{Fe}_{3} \mathrm{O}_{4}$ & $<100$ & Sph & $10-30 \mu \mathrm{g} / \mu \mathrm{L}$ & $\mathrm{MHA}, 24 \mathrm{~h}, 37^{\circ} \mathrm{C}$, & $\begin{array}{l}\text { E. coli, } \\
\text { K. pneumoniae, } \\
\text { P. aeruginosa, } \\
\text { S. aureus }\end{array}$ & BS & [80] \\
\hline
\end{tabular}

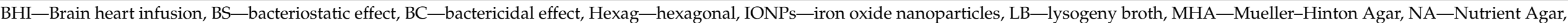

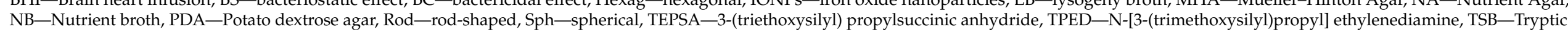

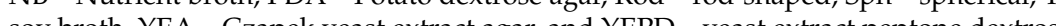


$\mathrm{Fe}_{3} \mathrm{O}_{4}$ NPs synthesized with a Couroupita guianensis extract inhibited the growth of $E$. coli, S. typhimurium, K. pneumoniae, and S. aureus and induced the apoptosis of the hepatocellular carcinoma (HepG2) cell line [81]. IONPs synthesized in a Ruellia tuberosa extract inhibited the growth of E. coli, K. pneumoniae, and S. aureus in a dose-dependent manner. The IONP effectiveness turned to be higher than that of streptomycin. The mechanism of antimicrobial action is the photocatalytic generation of $\mathrm{ROS}$ [74]. $\mathrm{Fe}_{2} \mathrm{O}_{3} /$ Citrus sinensis NPs exerted a comparable bacteriostatic action against Gram-positive (B. subtilis and S. aureus) and Gram-negative (E. coli and P. aeruginosa) bacteria. The inhibitory effect of $\mathrm{Fe}_{2} \mathrm{O}_{3} /$ Citrus sinensis NPs was comparable with chlorhexidine, hexachlorophene, benzalkonium chloride, and phenol taken in equal concentrations [121]. $\alpha-\mathrm{Fe}_{2} \mathrm{O}_{3} \mathrm{NPs}$, in combination with a Sida cordifolia extract, had comparable bacteriostatic activity against E. coli, K. pneumoniae, $B$. subtilis, and $S$. aureus. The bacteriostatic effect against Gram-positive bacteria was more strongly pronounced and was comparable with the effect of neomycin [119]. Unfortunately, for several extracts-for example, Couroupita guianensis- "green synthesis" leads to an enhancement of IONP cytotoxicity [81]. In another study, the antioxidant properties were described for $\mathrm{Fe}_{3} \mathrm{O}_{4}$ NPs synthesized by the "green method" [87]. In a meta-analysis, we found that IONPs generated by the "green synthesis" method had three times more pronounced bacteriostatic activity than IONPs generated by the coprecipitation method (Figure 2c).

\subsection{Additional Methods for Increasing the Antimicrobial Activity of IONPs}

Iron oxide nanoparticles have both magnetic and paramagnetic properties [68,87,102-104]. The use of an alternating magnetic field allows additional increases in the bactericidal action of $\mathrm{Fe}_{3} \mathrm{O}_{4}$ NPs against $E$. coli and $S$. aureus, causing cell death and biofilm destruction due to the photocatalytic generation of ROS, and local hyperthermia and vibration damage occurred under the action of the magnetic field. All of the above-mentioned factors lead to the dissociation of bacteria from the biofilm, damage of the bacterial cell wall, membrane rupture, the fusion of different cells with each other, and death [69].

$\mathrm{Fe}_{2} \mathrm{O}_{4}$ composite NPs with the addition of different ratios of $\mathrm{Co}$ and $\mathrm{Mn}$ have magnetic properties due to $\mathrm{Fe}_{2} \mathrm{O}_{4}$ and inhibit the growth of E. coli and cause damage to E. coli and B. subtilis in a dose-dependent manner [102].

IONP conjugation with carbon nanotubes allows achieving a bactericidal effect against Gram-negative (E. coli and K. pneumoniae) and Gram-positive (Staphylococcus aureus) bacteria; with that, the CFU were reduced by two and more times compared to the control [77]. Carbon nanotubes/IONPs accelerated wound healing in mice in a wound-healing test by $25 \%$ and $50 \%$ compared to IONPs or carbon nanotubes taken individually. It is worth noting that, in this study, the size of the inhibition zone increased insignificantly upon a considerable decrease in the CFU; therefore, the antimicrobial effect of IONPs assessed by a size of the inhibition zone in the majority of studies can be underestimated. In contrast to other IONPs types, $\mathrm{Fe}_{3} \mathrm{O}_{4}$ IONPs coated with oleic acid exert a different effect on the growth and viability of Gram-positive (Enterococcus hirae) and Gram-negative (E. coli) bacteria. More pronounced antimicrobial action was observed against Gram-negative bacteria [127]. The authors linked this phenomenon with differences in the cell wall structure; in particular, with the ability of $\mathrm{Fe}_{3} \mathrm{O}_{4}$ IONPs to concentrate between the outer and inner membranes of the cell wall in Gram-negative bacteria and the presence of the FHL complex in the inner membrane of E. coli, which is an additional target for IONP Fe${ }_{3} \mathrm{O}_{4} . \mathrm{Fe}_{3} \mathrm{O}_{4} \mathrm{NPs}$ covered with oleic acid cause a reduction in the growth of kanamycin- and ampicillin-resistant $E$. coli strains due to retardation of the logarithmic growth phase, lag phase extension, reduction of the $\mathrm{H}^{+}$flow through the membrane, and redox potential [85,131]. IONPs coated with oleic acid not only inhibit the growth of $S$. aureus and P. aeruginosa but also prevent biofilm formation [131].

Surface modification is also a key way to improve IONP the antibacterial properties [78] The conjugation of IONPs with chitosan enhanced the bactericidal action of IONPs against Bacillus subtilis and Escherichia coli due to ROS generation [78]. 
$\mathrm{Fe}_{3} \mathrm{O}_{4}$ NPs covered with polyethylene glycol (PEG) exert a dose-dependent bactericidal action against the E. coli and S. aureus and antibiotic-resistant Micrococcus luteus strain. The mechanism of toxicity resides in a decrease in the activity of the antioxidant system enzymes (SOD, catalase, and glutathione reductase) and, as a consequence, enhancement of ROS generation and lipid oxidation [67].

$\mathrm{Fe}_{3} \mathrm{O}_{4} \mathrm{NPs}$ conjugated with chitosan have bactericidal and fungicidal actions against Candida albicans, Aspergillus niger, and Fusarium solani [90]. Coating with alginate or tobramycin did not have a significant effect on the bacteriostatic activity of $\mathrm{Fe}_{3} \mathrm{O}_{4}$ NPs against P. aeruginosa [84].

Conjugation with polyethylene glycol (PEG) and chitosan allows not only improving the antimicrobial properties of IONPs but also reducing the undesirable adsorption of IONPs on liver macrophages [133,134].

One of the methods for improving the antimicrobial properties is the use of a combination of "green synthesis" and a change in the NP compositions-for example, the addition of gold. The bacteriostatic effect of the mixture Urtica $/ \alpha-\mathrm{Fe}_{2} \mathrm{O}_{3} \bullet \mathrm{Ag}$ NPs against S. aureus, Bacillus sp., Klebsiella sp., and E. coli was higher compared to Urtica $/ \alpha-\mathrm{Fe}_{2} \mathrm{O}_{3}$ NPs. An increase in the inhibition zone was proportional to the silver concentration in the composite. Both Urtica $/ \alpha-\mathrm{Fe}_{2} \mathrm{O}_{3} \bullet \mathrm{Ag}$ NPs and Urtica $/ \alpha-\mathrm{Fe}_{2} \mathrm{O}_{3} \mathrm{NPs}$ had more pronounced effects on the growth of the Gram-negative strains [36]. Some of the mechanisms of action of $\mathrm{Fe}_{3} \mathrm{O}_{4}$ and $\mathrm{Ag}$ NPs are membrane damage, a decrease in the redox potential, and $\mathrm{H}^{+}$ fluxes, which lead to the inhibition of the activity of bacterial $F_{o} / F_{1}$-ATPase [131].

The combined use of NPs from iron oxides and gold does not reduce the growth of the bacterial biomass of the E. coli culture but prevents bacterial cell division [75]; as a consequence, E. coli alters their morphology from rods to filaments with a length of several micrometers. The mixture of $\mathrm{Fe}_{3} \mathrm{O}_{4}$ and $\mathrm{Au}$ NPs inhibits the growth of the kanamycinresistant Escherichia coli and Salmonella typhimurium strains more effectively than $\mathrm{Fe}_{2} \mathrm{O}_{3}$ NPs [75].

An approach to an improvement in the antimicrobial properties of IONPs by their conjugation with antibiotics is described by the example of gentamicin [79]. With that, a more pronounced bacteriostatic effect was achieved against Gram-positive B. subtilis and S. aureus than Gram-negative E. coli and P. areuginosa. A conjugation with gentamicin reduced the minimum inhibitory concentration against all indicated strains by more than ten times [79]. In several cases, the conjugation of IONPs with antibiotics can give an opposite result. IONPs conjugated with amoxicillin enhanced the growth of Pseudomonas aeruginosa and Staphylococcus aureus [86]. The presence of organic acids (humic acid) additionally accelerates bacterial growth. In general, it is possible to significantly influence the antimicrobial activity of IONPs by additives, coatings, and conjugates, which, undoubtedly, can be promising in the development of this direction.

\subsection{Biocompatibility of IONPs}

It is shown that IONPs have good biocompatibility and biodegradability. In particular, the intravenous injection of $0.8 \mathrm{mg} / \mathrm{kg}$ of $\gamma-\mathrm{Fe}_{2} \mathrm{O}_{3} \mathrm{NPs}$ did not influence the weight gain in rats or cause the activation of apoptosis in HUVEC cells [61]. After intravenous injection, NPs were found in rat lungs, liver, and kidneys but not in the brain or heart. A significant proportion of NPs was eliminated with urine after $72 \mathrm{~h}$ [61]. In general, IONPs show an absence or low cytotoxic effects on cell cultures. For example, no adverse effect of IONPs coated with polyethyleneimine, dimercaptosuccinate, or citrate on primary rat cerebellar cortex astrocytes and cultured murine astrocytes was observed [62,135]. IONPs conjugated with PEG-phospholipids (WFION) did not influence the viability of the B16 F10 cell line at doses up to 0.75-mg Fe/mL [136]. $\mathrm{Fe}_{3} \mathrm{O}_{4}$ NPs show a bacteriostatic effect and, at the same time, do not exert a hemolytic action $[66,70]$. In several cases, IONPs enhance Casp3-dependent apoptosis in HUVEC cells, cause ROS generation, membrane damage, changes in the cytoskeleton, and so on [137]. In general, the cytotoxic properties of IONPs are manifested at much higher concentrations than the antimicrobial properties. 


\subsection{Disadvantages of IONPS}

The disadvantages of IONPs include relatively weak antimicrobial action against several strains and insufficient biocompatibility with eukaryotic cells. For example, $\mathrm{Fe}_{2} \mathrm{O}_{3}$ NPs inhibit the growth of Escherichia coli, Staphylococcus aureus, Pseudomonas aeruginosa, and Bacillus subtilis less effectively than $\mathrm{ZnO}$ and $\mathrm{CuO}$ NPs. The inhibitory action of $\mathrm{Fe}_{2} \mathrm{O}_{3}$ NPs on Escherichia coli growth was lower than that of $\mathrm{ZnO}$ and $\mathrm{CuO}$ NPs [138]. This effect may be explained by differences in the antibacterial properties of considered metals. Iron $\mathrm{Fe}^{2+}$ is necessary for the proliferation of bacteria [31]. $\mathrm{Fe}^{3+}$ inhibited E. coli growth in concentrations above $0.25-1 \mathrm{mM}$, but Fe ${ }^{3+}$ had only a bacteriostatic effect without bactericidal action [139]. $\mathrm{Zn}^{2+}$ and $\mathrm{Cu}^{+}$decrease the viability of Staphylococcus aureus and Escherichia coli in concentrations of 2.41 and $0.46 \mathrm{mM}$, respectively [140]. Fe NPs exert more pronounced bacteriostatic actions against Pseudomonas aeruginosa than $\mathrm{Fe}_{3} \mathrm{O}_{4} \mathrm{NPs}$ [84]. Lee et al. [97] did not observe the bactericidal action of $\mathrm{Fe}_{3} \mathrm{O}_{4}$ NPs against $E$. coli contrary to $\mathrm{Fe}$ $\mathrm{NPs}, \mathrm{Ag} \mathrm{NPs}$, or $\mathrm{FeSO}_{4} \mathrm{NPs}$. $\mathrm{Fe}^{2+}$ from IONPs in the presence of humic acid can enhance the growth of Pseudomonas aeruginosa [86]. The bacteriostatic action of $\mathrm{Fe}_{3} \mathrm{O}_{4} \mathrm{NPs}$ against various microbial species differs significantly [8]. $\mathrm{Fe}_{3} \mathrm{O}_{4} \mathrm{NPs}$ effectively inhibits the growth of Staphylococcus epidermidis, Staphylococcus aureus, Bacillus licheniformis, and Bacillus subtilis. The effect is comparable with the action of neomycin. With that, $\mathrm{Fe}_{3} \mathrm{O}_{4} \mathrm{NPs}$ are two times less effective at inhibiting the growth of Bacillus brevis and Vibrio cholerae than neomycin and absolutely do not influence the growth of Shigella flexneri and Pseudomonas aeruginosa.

Unfortunately, IONPs has not only bacteriostatic and bactericidal activities but toxicity for some eukaryotic cell lines [108]. The main mechanism of IONP toxicity is the production of ROS, which leads to increasing the level of lipid peroxidation, decreasing the antioxidant enzymes, and protein aggregation [141-144]. IONPs can lead to cell iron overload. Iron overload causes serious deleterious and leads to cell death [142,143]. In addition, a high dose of IONPs increases the lipid metabolism, the breakage of iron homeostasis, and exacerbates the loss of murine liver functions in vivo [145].

The IONP applications in biomedicine are limited due to a lack of control and prediction of the final IONP properties, such as IONP interactions with cells [146]. An important aspect of IONPs in biomedical applications is their surface chemistry [147]. The coating of IONPs by PEG reduces protein adsorption, increases stability to the IONPs, decreases the IONP uptake by culture cells in and by entire organisms in vivo, and increases IONP retention times in the blood flow [148-150]. Unfortunately, PEG can be oxidized by host enzymes, which leads to a loss of some PEG-IONP proteins [148]. Proteins are commonly the first biomolecules that IONPs encounter when they interact with biological systems in vitro or in vivo [146]. IONPs may be coated by bovine serum albumin (BSA) or fetal bovine serum [151]. BSA forms a protective layer on the NPs to improve the biocompatibility and transport of the IONPs. BSA-coated IONPs allow to accumulate the drug in the tumor due to an enhanced permeability and retention and to reduce the risk of hypersensitivity reactions [152]. Drugs released from BSA-coated IONPs can be triggered by protease digestion in target tissues, and finally, the unfolding BSA protein on the IONPs can facilitate their clearance by phagocytes after drug delivery [153]. Additionally, BSA coating supports the colloidal stability of the IONPs in cell culture experiments [151]. Multiple specialized characterization methods are widely used to characterize IONP surfaces: TEM,

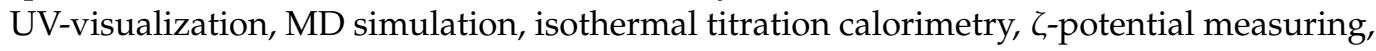
etc. [151]. The antibacterial properties of BSA-IONPs remain unclear.

\section{Conclusions}

IONPs have found wide applications in different fields of biomedicine. The antibacterial activities of IONPs are of special interest. However, the situation with the antimicrobial activities of IONPs is ambiguous. On the one hand, the antibacterial activities of IONPs depend, to a significant extent, on the microbial strain, and the inhibitory actions of IONPs are often less pronounced than that of NPs of other metal oxides ( $\mathrm{CuO}$ or $\mathrm{ZnO}$ ). On the other hand, IONPs show less-pronounced cytotoxic properties and better biocompatibility 
in vivo compared to $\mathrm{CuO}$ or $\mathrm{ZnO}$ NPs. We assume that, in the near future, IONPs will allow achieving a balance between antimicrobial actions and biocompatibility in vivo. In this case, IONPs can be considered potential antimicrobial agents of the new generation. Based on the analyzed data, we believe that the most promising method for increasing the antimicrobial properties of IONPs and improving biocompatibility is "green synthesis" and other variants of the additive or composite generation of nanoparticles.

Author Contributions: Conceptualization, S.V.G.; writing—original draft preparation, D.E.B., D.A.S., M.B.R., and S.V.G.; visualization, D.A.S.; supervision, A.A.S.; and project administration, A.B.L. All authors have read and agreed to the published version of the manuscript.

Funding: This research was funded by the Ministry of Science and Education of the Russian Federation, grant number 075-15-2020-775.

Institutional Review Board Statement: Not applicable.

Informed Consent Statement: Not applicable.

Data Availability Statement: The raw data supporting the conclusions of this article will be made available by the authors without undue reservation.

Conflicts of Interest: The authors declare no conflict of interest.

\section{References}

1. Wang, E.C.; Wang, A.Z. Nanoparticles and their applications in cell and molecular biology. Integr. Biol. 2014, 6, 9-26. [CrossRef]

2. Thakur, N.; Manna, P.; Das, J. Synthesis and biomedical applications of nanoceria, a redox active nanoparticle. J. Nanobiotechnol. 2019, 17, 84. [CrossRef] [PubMed]

3. Rajakumar, G.; Mao, L.; Bao, T.; Wen, W.; Wang, S.; Gomathi, T.; Gnanasundaram, N.; Rebezov, M.; Shariati, M.A.; Chung, I.-M.; et al. Yttrium Oxide Nanoparticle Synthesis: An Overview of Methods of Preparation and Biomedical Applications. Appl. Sci. 2021, 11, 2172. [CrossRef]

4. Ahmad, B.; Shireen, F.; Rauf, A.; Shariati, M.A.; Bashir, S.; Patel, S.; Khan, A.; Rebezov, M.; Khan, M.U.; Mubarak, M.S.; et al. Phyto-fabrication, purification, characterisation, optimisation, and biological competence of nano-silver. IET Nanobiotechnol. 2021, 15, 1-18. [CrossRef]

5. AlMatar, M.; Makky, E.A.; Var, I.; Koksal, F. The role of nanoparticles in the inhibition of multidrug-resistant bacteria and biofilms. Curr. Drug Deliv. 2018, 15, 470-484. [CrossRef]

6. $\mathrm{Su}, \mathrm{Y} . ; \mathrm{Wu}, \mathrm{D} . ; \mathrm{Xia}, \mathrm{H}$;; Zhang, C.; Shi, J.; Wilkinson, K.J.; Xie, B. Metallic nanoparticles induced antibiotic resistance genes attenuation of leachate culturable microbiota: The combined roles of growth inhibition, ion dissolution and oxidative stress. Environ. Int. 2019, 128, 407-416. [CrossRef] [PubMed]

7. Kim, J.S.; Kuk, E.; Yu, K.N.; Kim, J.H.; Park, S.J.; Lee, H.J.; Kim, S.H.; Park, Y.K.; Park, Y.H.; Hwang, C.Y.; et al. Antimicrobial effects of silver nanoparticles. Nanomedicine 2007, 3, 95-101. [CrossRef]

8. Saliani, M.; Jalal, R.; Goharshadi, K.E. Effects of $\mathrm{pH}$ and temperature on antibacterial activity of zinc oxide nanofluid against Escherichia coli O157: H7 and Staphylococcus aureus. Jundishapur J. Microbiol. 2015, 8, e17115. [CrossRef]

9. Behera, S.S.; Patra, J.K.; Pramanik, K.; Panda, N.; Thatoi, H. Characterization and evaluation of antibacterial activities of chemically synthesized iron oxide nanoparticles. World J. Nano Sci. Eng. 2012, 2, 196-200. [CrossRef]

10. Allahverdiyev, A.M.; Abamor, E.S.; Bagirova, M.; Rafailovich, M. Antimicrobial effects of $\mathrm{TiO}_{2}$ and $\mathrm{Ag}_{2} \mathrm{O}$ nanoparticles against drug-resistant bacteria and leishmania parasites. Future Microbiol. 2011, 6, 933-940. [CrossRef] [PubMed]

11. Khan, M.F.; Ansari, A.H.; Hameedullah, M.; Ahmad, E.; Husain, F.M.; Zia, Q.; Baig, U.; Zaheer, M.R.; Alam, M.M.; Khan, A.M.; et al. Sol-gel synthesis of thorn-like $\mathrm{ZnO}$ nanoparticles endorsing mechanical stirring effect and their antimicrobial activities: Potential role as nano-antibiotics. Sci. Rep. 2016, 6, 27689. [CrossRef]

12. Ren, G.; Hu, D.; Cheng, E.W.C.; Vargas-Reus, M.A.; Reip, P.; Allaker, R.P. Characterisation of copper oxide nanoparticles for antimicrobial applications. Int. J. Antimicrob. Agents 2009, 33, 587-590. [CrossRef] [PubMed]

13. Ahmed, T.; Wu, Z.; Jiang, H.; Luo, J.; Noman, M.; Shahid, M.; Manzoor, I.; Allemailem, K.S.; Alrumaihi, F.; Li, B. Bioinspired Green Synthesis of Zinc Oxide Nanoparticles from a Native Bacillus cereus Strain RNT6: Characterization and Antibacterial Activity against Rice Panicle Blight Pathogens Burkholderia glumae and B. gladioli. Nanomaterials 2021, 11, 884. [CrossRef]

14. Gudkov, S.V.; Burmistrov, D.E.; Serov, D.A.; Rebezov, M.E.; Semenova, A.A.; Lisitsyn, A.B. A mini review of antibacterial properties of ZnO nanoparticles. Front. Phys. 2021, 9, 641481. [CrossRef]

15. Pushcharovsky, D.Y. Iron and its compounds in the Earth's core: New data and ideas. Geochem. Int. 2019, 57, 941-955. [CrossRef]

16. Pilchin, A.; Eppelbaum, L.V. Iron and Its Unique Role in Earth Evolution, 1st ed.; Geoph. Society: Mexico City, Mexico, 2006; ISBN 970-32-4122-0.

17. Beinert, H.; Holm, R.H.; Munck, E. Iron-sulfur clusters: Nature's modular, multipurpose structures. Science 1997, 277, 653-659. [CrossRef] 
18. Andreini, C.; Bertini, I.; Cavallaro, G.; Holliday, G.L.; Thornton, J.M. Metal ions in biological catalysis: From enzyme databases to general principles. J. Biol. Inorg. Chem. 2008, 13, 1205-1218. [CrossRef]

19. Caza, M.; Kronstad, J.W. Shared and distinct mechanisms of iron acquisition by bacterial and fungal pathogens of humans. Front. Cell. Infect. Microbiol. 2013, 3, 80. [CrossRef]

20. Andrews, S.C.; Robinson, A.K.; Rodriguez-Quinones, F. Bacterial iron homeostasis. FEMS Microbiol. Rev. 2003, 27, 215-237. [CrossRef]

21. Bagg, A.; Neilands, J.B. Ferric uptake regulation protein acts as a repressor, employing iron (II) as a cofactor to bind the operator of an iron transport operon in Escherichia coli. Biochemistry 1987, 26, 5471-5477. [CrossRef] [PubMed]

22. Fink, R.C.; Evans, M.R.; Porwollik, S.; Vazquez-Torres, A.; Jones-Carson, J.; Troxell, B.; Libby, S.J.; McClelland, M.; Hassan, H.M. FNR is a global regulator of virulence and anaerobic metabolism in Salmonella enterica serovar Typhimurium (ATCC $14028 \mathrm{~s}$ ). J. Bacteriol. 2007, 189, 2262-2273. [CrossRef] [PubMed]

23. D'Autreaux, B.; Tucker, N.P.; Dixon, R.; Spiro, S. A non-haem iron centre in the transcription fac or NorR senses nitric oxide. Nature 2005, 437, 769-772. [CrossRef] [PubMed]

24. Pomposiello, P.J.; Demple, B. Identification of SoxS-regulated genes in Salmonella enterica serovar typhimurium. J. Bacteriol. 2000, 182, 23-29. [CrossRef] [PubMed]

25. Schwartz, C.J.; Giel, J.L.; Patschkowski, T.; Luther, C.; Ruzicka, F.J.; Beinert, H.; Kiley, P.J. IscR, an Fe-S cluster-containing transcription factor, represses expression of Escherichia coli genes encoding Fe-S cluster assembly proteins. Proc. Natl. Acad. Sci. USA 2001, 98, 14895-14900. [CrossRef] [PubMed]

26. Karlinsey, J.E.; Bang, I.S.; Becker, L.A.; Frawley, E.R.; Porwollik, S.; Robbins, H.F.; Thomas, V.C.; Urbano, R.; McClelland, M.; Fang, F.C. The NsrR regulon in nitrosative stress resistance of Salmonella enterica serovar Typhimurium. Mol. Microbiol. 2012, 85, 1179-1193. [CrossRef]

27. Amor, M.; Ceballos, A.; Wan, J.; Simon, C.P.; Aron, A.T.; Chang, C.J.; Hellman, F.; Komeili, A. Magnetotactic Bacteria Accumulate a Large Pool of Iron Distinct from Their Magnetite Crystals. Appl. Environ. Microbiol. 2020, 86, e01278-20. [CrossRef]

28. Uebe, R.; Schüler, D. Magnetosome biogenesis in magnetotactic bacteria. Nat. Rev. Microbiol. 2016, 14, 621-637. [CrossRef]

29. Smith, M.J.; Sheehan, P.E.; Perry, L.L.; O'Connor, K.; Csonka, L.N.; Applegate, B.M.; Whitman, L.J. Quantifying the magnetic advantage in magnetotaxis. Biophys. J. 2006, 91, 1098-1107. [CrossRef]

30. Emerson, D.; Fleming, E.J.; McBeth, J.M. Iron-oxidizing bacteria: An environmental and genomic perspective. Annu. Rev. Microbiol. 2010, 64, 561-583. [CrossRef]

31. Parrow, N.L.; Fleming, R.E.; Minnick, M.F. Sequestration and scavenging of iron in infection. Infect. Immun. 2013, 81, 3503-3514. [CrossRef]

32. Tran, N.; Mir, A.; Mallik, D.; Sinha, A.; Nayar, S.; Webster, T.J. Bactericidal effect of iron oxide nanoparticles on Staphylococcus aureus. Int. J. Nanomed. 2010, 5, 277-283. [CrossRef]

33. Saqib, S.; Munis, M.F.H.; Zaman, W.; Ullah, F.; Shah, S.N.; Ayaz, A.; Farooq, M.; Bahadur, S. Synthesis, characterization and use of iron oxide nano particles for antibacterial activity. Microsc. Res. Tech. 2019, 82, 415-420. [CrossRef] [PubMed]

34. Fenton, H.J.H. Oxidation of tartaric acid in presence of iron. J. Chem. Soc. 1894, 65, 899-911. [CrossRef]

35. Frawley, E.R.; Fang, F.C. The ins and outs of bacterial iron metabolism. Mol. Microbiol. 2014, 93, 609-616. [CrossRef]

36. Sihem, L.; Hanine, D.; Faiza, B. Antibacterial Activity of $\alpha-\mathrm{Fe}_{2} \mathrm{O}_{3}$ and $\alpha-\mathrm{Fe}_{2} \mathrm{O}_{3} @ \mathrm{Ag}$ Nanoparticles Prepared by Urtica Leaf Extract. Nanotechnol. Russ. 2020, 15, 198-203. [CrossRef]

37. Li, D.; Shen, M.; Xia, J.; Shi, X. Recent developments of cancer nanomedicines based on ultrasmall iron oxide nanoparticles and nanoclusters. Nanomedicine 2021, 16, 609-612. [CrossRef]

38. Baimler, I.V.; Lisitsyn, A.B.; Serov, D.A.; Astashev, M.E.; Gudkov, S.V. Analysis of acoustic signals during the optical breakdown of aqueous solutions of Fe nanoparticles. Front. Phys. 2020, 8, 622551. [CrossRef]

39. Gudkov, S.V.; Baimler, I.V.; Uvarov, O.V.; Smirnova, V.V.; Volkov, M.Y.; Semenova, A.A.; Lisitsyn, A.B. Influence of the concentration of $\mathrm{Fe}$ and $\mathrm{Cu}$ nanoparticles on the dynamics of the size distribution of nanoparticles. Front. Phys. 2020, $8,622551$. [CrossRef]

40. Baimler, I.V.; Lisitsyn, A.B.; Gudkov, S.V. Water decomposition occurring during laser breakdown of aqueous solutions containing individual gold, zirconium, molybdenum, iron or nickel nanoparticles. Front. Phys. 2020, 8, 620938. [CrossRef]

41. Stolyar, S.V.; Krasitskaya, V.V.; Frank, L.A.; Yaroslavtsev, R.N.; Chekanova, L.A.; Gerasimova, Y.V.; Volochaev, M.N.; Bairmani, M.S.; Velikanov, D.A. Polysaccharide-coated iron oxide nanoparticles: Synthesis, properties, surface modification. Mater. Lett. 2021, 284, 128920. [CrossRef]

42. Tyurikova, I.A.; Alexandrov, S.E.; Tyurikov, K.S.; Kirilenko, D.A.; Speshilova, A.B.; Shakhmin, A.L. Fast and controllable synthesis of core-shell $\mathrm{Fe}_{3} \mathrm{O}_{4}-\mathrm{C}$ nanoparticles by aerosol CVD. ACS Omega 2020, 5, 8146-8150. [CrossRef]

43. Lozhkomoev, A.S.; Pervikov, A.V.; Kazantsev, S.O.; Sharipova, A.F.; Rodkevich, N.G.; Toropkov, N.E.; Suliz, K.V.; Svarovskaya, N.V.; Kondranova, A.M.; Lerner, M.I. Synthesis of $\mathrm{Fe} / \mathrm{Fe}_{3} \mathrm{O}_{4}$ core-shell nanoparticles by electrical explosion of the iron wire in an oxygen-containing atmosphere. J. Nanopart. Res. 2021, 23, 73. [CrossRef]

44. Xie, J.; Chen, K.; Huang, J.; Lee, S.; Wang, J.; Gao, J.; Li, X.; Chen, X. PET/NIRF/MRI triple functional iron oxide nanoparticles. Biomaterials 2010, 31, 3016-3022. [CrossRef]

45. Emily, A. Waters SAW Contrast agents for MRI. Basic Res. Cardiol. 2008, 103, 114-121. [CrossRef] 
46. Liu, J.; Xu, J.; Zhou, J.; Zhang, Y.; Guo, D.; Wang, Z. Fe $\mathrm{F}_{3} \mathrm{O}_{4}$-based PLGA nanoparticles as MR contrast agents for the detection of thrombosis. Int. J. Nanomed. 2017, 12, 1113-1126. [CrossRef]

47. Cormode, D.P.; Naha, P.C.; Fayad, Z.A. Nanoparticle contrast agents for computed tomography: A focus on micelles. Contrast Media Mol. Imaging 2014, 9, 37-52. [CrossRef] [PubMed]

48. Thomas, R.; Park, I.K.; Jeong, Y.Y. Magnetic iron oxide nanoparticles for multimodal imaging and therapy of cancer. Int. J. Mol. Sci. 2013, 14, 15910-15930. [CrossRef]

49. Torres Martin de Rosales, R.; Tavaré, R.; Paul, R.L.; Jauregui-Osoro, M.; Protti, A.; Glaria, A.; Varma, G.; Szanda, I.; Blower, P.J. Synthesis of $64 \mathrm{Cu}(\mathrm{II})$-bis(dithiocarbamatebisphosphonate) and its conjugation with superparamagnetic iron oxide nanoparticles: In vivo evaluation as dual-modality PET-MRI agent. Angew. Chem. Int. Ed. Engl. 2011, 50, 5509-5513. [CrossRef]

50. Espinosa, A.; Di Coratom, R.; Kolosnjaj-Tabi, J.; Flaud, P.; Pellegrino, T.; Wilhelm, C. Duality of iron oxide nanoparticles in cancer therapy: Amplification of heating efficiency by magnetic hyperthermia and photothermal bimodal treatment. ACS Nano 2016, 10, 2436-2446. [CrossRef]

51. Vilas-Boas, V.; Espiña, B.; Kolen'ko, Y.V.; Bañobre-López, M.; Brito, M.; Martins, V.; Duarte, J.A.; Petrovykh, D.Y.; Freitas, P.; Carvalho, F. Effectiveness and safety of a nontargeted boost for a CXCR4-targeted magnetic hyperthermia treatment of cancer cells. ACS Omega 2019, 4, 1931-1940. [CrossRef]

52. Vilas-Boas, V.; Carvalho, F.; Espiña, B. Magnetic hyperthermia for cancer treatment: Main parameters affecting the outcome of in vitro and in vivo studies. Molecules 2020, 25, 2874. [CrossRef]

53. Shen, S.; Kong, F.; Guo, X.; Wu, L.; Shen, H.; Xie, M.; Wang, X.; Jin, Y.; Ge, Y. CMCTS stabilized $\mathrm{Fe}_{3} \mathrm{O}_{4}$ particles with extremely low toxicity as highly efficient near-infrared photothermal agents for in vivo tumor ablation. Nanoscale 2013, 5, 8056-8066. [CrossRef]

54. Tamanaha, C.R.; Mulvaney, S.P.; Rife, J.C.; Whitman, L.J. Magnetic labeling, detection, and system integration. Biosens. Bioelectron. 2008, 24, 1-13. [CrossRef]

55. Freitas, P.P.; Cardoso, F.A.; Martins, V.C.; Martins, S.A.; Loureiro, J.; Amaral, J.; Chaves, R.C.; Cardoso, S.; Fonseca, L.P.; Sebastião, A.M.; et al. Spintronic platforms for biomedical applications. Lab Chip 2012, 12, 546-557. [CrossRef]

56. Kaushik, A.; Khan, R.; Solanki, P.R.; Pandey, P.; Alam, J.; Ahmad, S.; Malhotra, B. Iron oxide nanoparticles-chitosan composite based glucose biosensor. Biosens. Bioelectron. 2008, 24, 676-683. [CrossRef]

57. Guldris, N.; Argibay, B.; Gallo, J.; Iglesias-Rey, R.; Carbó-Argibay, E.; Kolen'ko, Y.V.; Campos, F.; Sobrino, T.; Salonen, L.M.; Bañobre-López, M.; et al. Magnetite nanoparticles for stem cell labeling with high efficiency and long-term in vivo tracking. Bioconjug. Chem. 2017, 28, 362-370. [CrossRef]

58. Arachchige, M.P.; Laha, S.S.; Naik, A.R.; Lewis, K.T.; Naik, R.; Jena, B.P. Functionalized nanoparticles enable tracking the rapid entry and release of doxorubicin in human pancreatic cancer cells. Micron 2017, 92, 25-31. [CrossRef]

59. Borroni, E.; Miola, M.; Ferraris, S.; Ricci, G.; Zuzek Rozman, K.; Kostevsek, N.; Catizone, A.; Rimondini, L.; Prat, M.; Verne, E.; et al. Tumor targeting by lentiviral vectors combined with magnetic nanoparticles in mice. Acta Biomater. $2017,59,303-316$. [CrossRef]

60. Markides, H.; Rotherham, M.; El Haj, A.J. Biocompatibility and toxicity of magnetic nanoparticles in regenerative medicine. J. Nanomater. 2012, 13. [CrossRef]

61. Hanini, A.; Schmitt, A.; Kacem, K.; Chau, F.; Ammar, S.; Gavard, J. Evaluation of iron oxide nanoparticle biocompatibility. Int. J. Nanomed. 2011, 6, 787-794. [CrossRef]

62. Yiu, H.H.; Pickard, M.R.; Olariu, C.I.; Williams, S.R.; Chari, D.M.; Rosseinsky, M.J. $\mathrm{Fe}_{3} \mathrm{O}_{4}$-PEI-RITC magnetic nanoparticles with imaging and gene transfer capability: Development of a tool for neural cell transplantation therapies. Pharm. Res. 2012, 29, 1328-1343. [CrossRef]

63. Gong, Y.; Ji, Y.; Liu, F.; Li, J.; Cao, Y. Cytotoxicity, oxidative stress and inflammation induced by ZnO nanoparticles in endothelial cells: Interaction with palmitate or lipopolysaccharide. J. Appl. Toxicol. 2017, 37, 895-901. [CrossRef] [PubMed]

64. Bai, X.; Li, L.; Liu, H.; Tan, L.; Liu, T.; Meng, X. Solvothermal synthesis of ZnO nanoparticles and anti-infection application in vivo. ACS Appl. Mater. Interfaces 2015, 7, 1308-1317. [CrossRef]

65. Kanoksil, M.; Jatapai, A.; Peacock, S.J.; Limmathurotsakul, D. Epidemiology, microbiology and mortality associated with community-acquired bacteremia in northeast Thailand: A multicenter surveillance study. PLoS ONE 2013, 8, e54714. [CrossRef]

66. Gabrielyan, L.; Hovhannisyan, A.; Gevorgyan, V.; Ananyan, M.; Trchounian, A. Antibacterial effects of iron oxide $\left(\mathrm{Fe}_{3} \mathrm{O}_{4}\right)$ nanoparticles: Distinguishing concentration-dependent effects with different bacterial cells growth and membrane-associated mechanisms. Appl. Microbiol. Biotechnol. 2019, 103, 2773-2782. [CrossRef]

67. Janani, B.; Al-Mohaimeed, A.M.; Raju, L.L.; Al Farraj, D.A.; Thomas, A.M.; Khan, S.S. Synthesis and characterizations of hybrid $\mathrm{PEG}-\mathrm{Fe}_{3} \mathrm{O}_{4}$ nanoparticles for the efficient adsorptive removal of dye and antibacterial, and antibiofilm applications. J. Environ. Health Sci. Eng. 2021, 1-12. [CrossRef]

68. Rufus, A.; Sreeju, N.; Philip, D. Synthesis of biogenic hematite $\left(\alpha-\mathrm{Fe}_{2} \mathrm{O}_{3}\right)$ nanoparticles for antibacterial and nanofluid applications. RSC Adv. 2016, 6, 94206-94217. [CrossRef]

69. Li, W.; Wei, W.; Wu, X.; Zhao, Y.; Dai, H. The antibacterial and antibiofilm activities of mesoporous hollow $\mathrm{Fe}_{3} \mathrm{O}_{4}$ nanoparticles in an alternating magnetic field. Biomater. Sci. 2020, 8, 4492-4507. [CrossRef]

70. Irshad, R.; Tahir, K.; Li, B.; Ahmad, A.; Siddiqui, A.R.; Nazir, S. Antibacterial activity of biochemically capped iron oxide nanoparticles: A view towards green chemistry. J. Photochem. Photobiol. B 2017, 170, 241-246. [CrossRef] 
71. Al-Shabib, N.A.; Husain, F.M.; Ahmed, F.; Khan, R.A.; Khan, M.S.; Ansari, F.A.; Alam, M.Z.; Ahmed, M.A.; Khan, M.S.; Baig, M.H.; et al. Low temperature synthesis of superparamagnetic iron oxide $\left(\mathrm{Fe}_{3} \mathrm{O}_{4}\right)$ nanoparticles and their ROS mediated inhibition of biofilm formed by food-associated bacteria. Front. Microbiol. 2018, 9, 2567. [CrossRef]

72. Fracasso, G.; Ghigna, P.; Nodari, L.; Agnoli, S.; Badocco, D.; Pastore, P.; Nicolato, E.; Marzola, P.; Mihajlovi'c, D.; Markovic, M.; et al. Nanoaggregates of iron poly-oxo-clusters obtained by laser ablation in aqueous solution of phosphonates. J. Colloid Interface Sci. 2018, 522, 208-216. [CrossRef]

73. Arokiyaraj, S.; Saravanan, M.; Prakash, N.U.; Arasu, M.V.; Vijayakumar, B.; Vincent, S. Enhanced antibacterial activity of iron oxide magnetic nanoparticles treated with Argemone mexicana L. leaf extract: An in vitro study. Mater. Res. Bull. 2013, 48, 3323-3327. [CrossRef]

74. Vasantharaj, S.; Sathiyavimal, S.; Senthilkumar, P.; LewisOscar, F.; Pugazhendhi, A. Biosynthesis of iron oxide nanoparticles using leaf extract of Ruellia tuberosa: Antimicrobial properties and their applications in photocatalytic degradation. J. Photochem. Photobiol. B 2019, 192, 74-82. [CrossRef]

75. Chatterjee, S.; Bandyopadhyay, A.; Sarkar, K. Effect of iron oxide and gold nanoparticles on bacterial growth leading towards biological application. J. Nanobiotechnol. 2011, 9, 34. [CrossRef]

76. Bhushan, M.; Kumar, Y.; Periyasamy, L.; Viswanath, A.K. Antibacterial applications of $\alpha-\mathrm{Fe}_{2} \mathrm{O}_{3} / \mathrm{Co}_{3} \mathrm{O}_{4}$ nanocomposites and study of their structural, optical, magnetic and cytotoxic characteristics. Appl. Nanosci. 2018, 8, 137-153. [CrossRef]

77. Khashan, K.S.; Sulaiman, G.M.; Mahdi, R. Preparation of iron oxide nanoparticles-decorated carbon nanotube using laser ablation in liquid and their antimicrobial activity. Artif. Cells Nanomed. Biotechnol. 2017, 45, 1699-1709. [CrossRef] [PubMed]

78. Arakha, M.; Pal, S.; Samantarrai, D.; Panigrahi, T.K.; Mallick, B.C.; Pramanik, K.; Mallick, B.; Jha, S. Antimicrobial activity of iron oxide nanoparticle upon modulation of nanoparticle-bacteria interface. Sci. Rep. 2015, 5, 14813. [CrossRef] [PubMed]

79. Bhattacharya, P.; Neogi, S. Gentamicin coated iron oxide nanoparticles as novel antibacterial agents. Mater. Res. Express 2017, 4, 095005. [CrossRef]

80. Amutha, S.; Sridhar, S. Green synthesis of magnetic iron oxide nanoparticle using leaves of Glycosmis mauritiana and their antibacterial activity against human pathogens. J. Innov. Pharm. Biol. Sci. 2015, 29, 22-26. [CrossRef]

81. Sathishkumar, G.; Logeshwaran, V.; Sarathbabu, S.; Jha, P.K.; Jeyaraj, M.; Rajkuberan, C.; Senthilkumar, N.; Sivaramakrishnan, S. Green synthesis of magnetic $\mathrm{Fe}_{3} \mathrm{O}_{4}$ nanoparticles using Couroupita guianensis Aubl. fruit extract for their antibacterial and cytotoxicity activities. Artif. Cells Nanomed. Biotechnol. 2018, 46, 589-598. [CrossRef]

82. Mousavi, S.M.; Hashemi, S.A.; Zarei, M.; Bahrani, S.; Savardashtaki, A.; Esmaeili, H.; Lai, C.W.; Mazraedoost, S.; Abassi, M.; Ramavandi, B. Data on cytotoxic and antibacterial activity of synthesized $\mathrm{Fe}_{3} \mathrm{O}_{4}$ nanoparticles using Malva sylvestris. Data Brief 2019, 28, 104929. [CrossRef]

83. Prabhu, Y.T.; Rao, K.V.; Kumari, B.S.; Kumar, V.S.S.; Pavani, T. Synthesis of $\mathrm{Fe}_{3} \mathrm{O}_{4}$ nanoparticles and its antibacterial application. Int. Nano Lett. 2015, 5, 85-92. [CrossRef]

84. Armijo, L.M.; Wawrzyniec, S.J.; Kopciuch, M.; Brandt, Y.I.; Rivera, A.C.; Withers, N.J.; Cook, N.C.; Huber, D.L.; Monson, T.C.; Smyth, H.D.C.; et al. Antibacterial activity of iron oxide, iron nitride, and tobramycin conjugated nanoparticles against Pseudomonas aeruginosa biofilms. J. Nanobiotechnol. 2020, 18, 35. [CrossRef] [PubMed]

85. Velusamy, P.; Chia-Hung, S.; Shritama, A.; Kumar, G.V.; Jeyanthi, V.; Pandian, K. Synthesis of oleic acid coated iron oxide nanoparticles and its role in anti-biofilm activity against clinical isolates of bacterial pathogens. J. Taiwan Inst. Chem. Eng. 2016, 59, 450-456. [CrossRef]

86. Current, K.M.; Dissanayake, N.M.; Obare, S.O. Effect of iron oxide nanoparticles and amoxicillin on bacterial growth in the presence of dissolved organic carbon. Biomedicines 2017, 5, 55. [CrossRef] [PubMed]

87. Patra, J.K.; Ali, M.S.; Oh, I.G.; Baek, K.H. Proteasome inhibitory, antioxidant, and synergistic antibacterial and anticandidal activity of green biosynthesized magnetic $\mathrm{Fe}_{3} \mathrm{O}_{4}$ nanoparticles using the aqueous extract of corn (Zea mays L.) ear leaves. Artif. Cells Nanomed. Biotechnol. 2017, 45, 349-356. [CrossRef]

88. Groiss, S.; Selvaraj, R.; Varadavenkatesan, T.; Vinayagam, R. Structural characterization, antibacterial and catalytic effect of iron oxide nanoparticles synthesised using the leaf extract of Cynometra ramiflora. J. Mol. Struct. 2017, 1128, 572-578. [CrossRef]

89. Javanbakht, T.; Laurent, S.; Stanicki, D.; Wilkinson, K.J. Relating the surface properties of superparamagnetic iron oxide nanoparticles (SPIONs) to their bactericidal effect towards a biofilm of Streptococcus mutans. PLoS ONE 2016, 11, e0154445. [CrossRef]

90. Nehra, P.; Chauhan, R.P.; Garg, N.; Verma, K. Antibacterial and antifungal activity of chitosan coated iron oxide nanoparticles. Br. J. Biomed. Sci. 2018, 75, 13-18. [CrossRef]

91. Ismail, R.A.; Sulaiman, G.M.; Abdulrahman, S.A.; Marzoog, T.R. Antibacterial activity of magnetic iron oxide nanoparticles synthesized by laser ablation in liquid. Mater. Sci. Eng. C Mater. Biol. Appl. 2015, 53, 286-297. [CrossRef]

92. Bezza, F.A.; Tichapondwa, S.M.; Chirwa, E.M.N. Fabrication of monodispersed copper oxide nanoparticles with potential application as antimicrobial agents. Sci. Rep. 2020, 10, 16680. [CrossRef] [PubMed]

93. Yusof, N.A.A.; Zain, N.M.; Pauzi, N. Synthesis of ZnO nanoparticles with chitosan as stabilizing agent and their antibacterial properties against Gram-positive and Gram-negative bacteria. Int. J. Biol. Macromol. 2019, 124, 1132-1136. [CrossRef]

94. Kohanski, M.A.; DePristo, M.A.; Collins, J.J. Sublethal antibiotic treatment leads to multidrug resistance via radical-induced mutagenesis. Mol. Cell 2010, 37, 311-320. [CrossRef] [PubMed] 
95. Yu, J.; Zhang, W.; Li, Y.; Wang, G.; Yang, L.; Jin, J.; Huang, M. Synthesis, characterization, antimicrobial activity and mechanism of a novel hydroxyapatite whisker/nano zinc oxide biomaterial. Biomed. Mater. 2014, 10, 015001. [CrossRef]

96. Sousa, C.; Sequeira, D.; Kolen'ko, Y.V.; Pinto, I.M.; Petrovykh, D.Y. Analytical protocols for separation and electron microscopy of nanoparticles interacting with bacterial cells. Anal. Chem. 2015, 87, 4641-4648. [CrossRef]

97. Lee, C.; Kim, J.Y.; Lee, W.I.; Nelson, K.L.; David, L.; Sedlak, D.L. Bactericidal effect of zero-valent iron nanoparticles on Escherichia coli. Environ. Sci. Technol. 2008, 42, 4927-4933. [CrossRef]

98. Guittat, L.; Alberti, P.; Rosu, F.; Van Miert, S.; Thetiot, E.; Pieters, L.; Gabelica, V.; De Pauw, E.; Ottaviani, A.; Riou, J.F.; et al. Interactions of cryptolepine and neocryptolepine with unusual DNA structures. Biochimie 2003, 85, 535-547. [CrossRef]

99. Li, Y.; Yang, D.; Wang, S.; Li, C.; Xue, B.; Yang, L.; Shen, Z.; Jin, M.; Wang, J.; Qiu, Z. The detailed bactericidal process of ferric oxide nanoparticles on E. coli. Molecules 2018, 23, 606. [CrossRef]

100. Morones, J.R.; Elechiguerra, J.L.; Camacho, A.; Holt, K.; Kouri, J.B.; Ramírez, J.T.; Yacaman, M.J. The bactericidal effect of silver nanoparticles. Nanotechnology 2005, 16, 2346-2353. [CrossRef] [PubMed]

101. Nel, A.E.; Mädler, L.; Velegol, D.; Xia, T.; Hoek, E.M.; Somasundaran, P.; Klaessig, F.; Castranova, V.; Thompson, M. Understanding biophysicochemical interactions at the nano-bio interface. Nat. Mater. 2009, 8, 543-557. [CrossRef] [PubMed]

102. Margabandhu, M.; Sendhilnathan, S.; Maragathavalli, S.; Karthikeyan, V.; Annadurai, B. Synthesis characterization and antibacterial activity of iron oxide nanoparticles. Glob. J. Bio-Sci. Biotechnol. 2015, 4, 335-341.

103. Kolen'ko, Y.V.; Bañobre-López, M.; Rodríguez-Abreu, C.; Carbó-Argibay, E.; Sailsman, A.; Piñeiro-Redondo, Y.; Cerqueira, M.F.; Petrovykh, D.Y.; Kovnir, K.; Lebed, O.A.; et al. Large-scale synthesis of colloidal $\mathrm{Fe}_{3} \mathrm{O}_{4}$ nanoprticles exhibiting high heating efficiency in magnetic hyperthermia. J. Phys. Chem. C 2014, 118, 8691-8701. [CrossRef]

104. Kolen'ko, Y.V.; Bañobre-López, M.; Rodríguez-Abreu, C.; Carbó-Argibay, E.; Deepak, F.L.; Petrovykh, D.Y.; Cerqueira, M.F.; Kamali, S.; Kovnir, K.; Shtansky, D.V.; et al. High-temperature magnetism as a probe for structural and compositional uniformity in ligand-capped magnetite nanoparticles. J. Phys. Chem. C Nanomater. Interfaces 2014, 118, 28322-28329. [CrossRef] [PubMed]

105. Ali, A.; Zafar, H.; Zia, M.; Ul Haq, I.; Phull, A.R.; Ali, J.S.; Hussain, A. Synthesis, characterization, applications, and challenges of iron oxide nanoparticles. Nanotechnol. Sci. Appl. 2016, 9, 49-67. [CrossRef] [PubMed]

106. Toropova, Y.G.; Zelinskaya, I.A.; Gorshkova, M.N.; Motorina, D.S.; Korolev, D.V.; Velikonivtsev, F.S.; Gareev, K.G. Albumin covering maintains endothelial function upon magnetic iron oxide nanoparticles intravenous injection in rats. J. Biomed. Mater. Res. Part A 2021. [CrossRef] [PubMed]

107. Omelchenko, A.; Sobol, E.; Simakin, A.; Serkov, A.; Sukhov, I.; Shafeev, G. Biofunctional magnetic 'core-shell' nanoparticles generated by laser ablation of iron in liquid. Laser Phys. 2015, 25, 025607. [CrossRef]

108. Arias, L.S.; Pessan, J.P.; Vieira, A.P.M.; Lima, T.M.T.; Delbem, A.C.B.; Monteiro, D.R. Iron Oxide Nanoparticles for Biomedical Applications: A Perspective on Synthesis, Drugs, Antimicrobial Activity, and Toxicity. Antibiotics 2018, 7, 46. [CrossRef] [PubMed]

109. Wu, W.; Wu, Z.; Yu, T.; Jiang, C.; Kim, W.S. Recent progress on magnetic iron oxide nanoparticles: Synthesis, surface functional strategies and biomedical applications. Sci. Technol. Adv. Mater. 2015, 16, 023501. [CrossRef]

110. Kansara, K.; Patel, P.; Shukla, R.K.; Pandya, A.; Shanker, R.; Kumar, A.; Dhawan, A. Synthesis of biocompatible iron oxide nanoparticles as a drug delivery vehicle. Int. J. Nanomed. 2018, 13, 79-82. [CrossRef] [PubMed]

111. Huang, Y.; Mao, K.; Zhang, B.; Zhao, Y. Superparamagnetic iron oxide nanoparticles conjugated with folic acid for dual target-specific drug delivery and MRI in cancer theranostics. Mater. Sci. Eng. C Mater. Biol. Appl. 2017, 70, 763-771. [CrossRef]

112. Riaz, S.; Bashir, M.; Naseem, S. Iron oxide nanoparticles prepared by modified co-precipitation method. IEEE Trans. Magn. 2014, 50,1-4. [CrossRef]

113. Maity, D.; Ding, J.; Xue, J.M. Synthesis of magnetite nanoparticles by thermal decomposition: Time, temperature, surfactant and solvent effects. Funct. Mater. Lett. 2008, 1, 189-193. [CrossRef]

114. Yu, W.W.; Falkner, J.C.; Yavuz, C.T.; Colvin, V.L. Synthesis of monodisperse iron oxide nanocrystals by thermal decomposition of iron carboxylate salts. Chem. Commun. 2004, 10, 2306-2307. [CrossRef]

115. Hatakeyama, M.; Kishi, H.; Kita, Y.; Imai, K.; Nishio, K.; Karasawa, S.; Masaike, Y.; Sakamoto, S.; Sandhu, A.; Tanimoto, A.; et al. A two-step ligand exchange reaction generates highly water-dispersed magnetic nanoparticles for biomedical applications. $J$. Mater. Chem. 2011, 21, 5959-5966. [CrossRef]

116. Pandey, S.; Mishra, S.B. Sol-gel derived organic-inorganic hybrid materials: Synthesis, characterizations and applications. J. Sol-Gel Sci. Technol. 2011, 59, 73-94. [CrossRef]

117. Xu, J.K.; Zhang, F.F.; Sun, J.J.; Sheng, J.; Wang, F.; Sun, M. Bio and nanomaterials based on $\mathrm{Fe}_{3} \mathrm{O}_{4}$. Molecules 2014, 19, $21506-21528$. [CrossRef]

118. Amendola, V.; Meneghetti, M. What controls the composition and the structure of nanomaterials generated by laser ablation in liquid solution? Phys. Chem. Chem. Phys. 2013, 15, 3027-3046. [CrossRef]

119. Pallela, P.N.V.K.; Ummey, S.; Ruddaraju, L.K.; Gadi, S.; Cherukuri, C.S.; Barla, S.; Pammi, S.V.N. Antibacterial efficacy of green synthesized $\alpha-\mathrm{Fe}_{2} \mathrm{O}_{3}$ nanoparticles using Sida cordifolia plant extract. Heliyon 2019, 5, e02765. [CrossRef]

120. Senthil, M.; Ramesh, C. Biogenic synthesis of $\mathrm{Fe}_{3} \mathrm{O}_{4}$ nanoparticles using Tridax procumbens leaf extract and its antibacterial activity on Pseudomonas aeruginosa. Dig. J. Nanomater. Biostruct. 2012, 7, 1655-1660.

121. Bashir, M.; Ali, S.; Farrukh, M.A. Green synthesis of $\mathrm{Fe}_{2} \mathrm{O}_{3}$ nanoparticles from orange peel extract and a study of its antibacterial activity. J. Korean Phys. Soc. 2020, 76, 848-854. [CrossRef] 
122. Mahmoudi, M.; Sant, S.; Wang, B.; Laurent, S.; Sen, T. Superparamagnetic iron oxide nanoparticles (SPIONs): Development, surface modification and applications in chemotherapy. Adv. Drug Deliv. Rev. 2011, 63, 24-46. [CrossRef]

123. Lu, A.H.; Salabas, E.L.; Schüth, F. Magnetic nanoparticles: Synthesis, protection, functionalization, and application. Angew. Chem. Int. Ed. Engl. 2007, 46, 1222. [CrossRef]

124. Maji, S.K.; Mukherjee, N.; Mondal, A.; Adhikary, B. Synthesis, characterization and photocatalytic activity of $\alpha-\mathrm{Fe}_{2} \mathrm{O}_{3}$ nanoparticles. Polyhedron 2012, 33, 145-149. [CrossRef]

125. Mohapatra, M.; Anand, S. Synthesis and applications of nano-structured iron oxides/hydroxides-a review. Int. J. Eng. Sci. Technol. 2010, 2, 127-146. [CrossRef]

126. Upadhyay, S.; Parekh, K.; Pandey, B. Influence of crystallite size on the magnetic properties of $\mathrm{Fe}_{3} \mathrm{O}_{4}$ nanoparticles. J. Alloys Compd. 2016, 678, 478-485. [CrossRef]

127. Gabrielyan, L.; Hakobyan, L.; Hovhannisyan, A.; Trchounian, A. Effects of iron oxide $\left(\mathrm{Fe}_{3} \mathrm{O}_{4}\right)$ nanoparticles on Escherichia coli antibiotic-resistant strains. J. Appl. Microbiol. 2019, 126, 1108-1116. [CrossRef] [PubMed]

128. Awwad, A.M.; Salem, N.M. A green and facile approach for synthesis of magnetite nanoparticles. Nanosci. Nanotechnol. 2012, 2, 208-213. [CrossRef]

129. Soenen, S.J.; Himmelreich, U.; Nuytten, N.; De Cuyper, M. Cytotoxic effects of iron oxide nanoparticles and implications for safety in cell labelling. Biomaterials 2011, 32, 195-205. [CrossRef]

130. Naeimi, H.; Nazifi, Z.S.; Amininezhad, S.M. Preparation of $\mathrm{Fe}_{3} \mathrm{O}_{4}$ encapsulated-silica sulfonic acid nanoparticles and study of their in vitro antimicrobial activity. J. Photochem. Photobiol. B 2015, 149, 180-188. [CrossRef]

131. Gabrielyan, L.; Badalyan, H.; Gevorgyan, V.; Trchounian, A. Comparable antibacterial effects and action mechanisms of silver and iron oxide nanoparticles on Escherichia coli and Salmonella typhimurium. Sci. Rep. 2020, 10, 13145. [CrossRef] [PubMed]

132. Ansari, S.A.; Oves, M.; Star, R.; Khan, A.; Ahmad, S.A.; Jafri, M.A.; Zaidi, S.K.; Algahtani, M.H.; Star, R.; Khan, A.; et al. Antibacterial activity of iron oxide nanoparticles synthesized by co-precipitation technology against Bacillus cereus and Klebsiella pneumonia. Polish J. Chem. Technol. 2017, 19, 110-115. [CrossRef]

133. Lee, C.; Jeon, H.; Kim, S.; Kim, E.; Kim, D.W.; Lim, S.T.; Jang, K.Y.; Jeong, Y.Y.; Nah, J.W.; Sohn, M. SPION-loaded chitosan-linoleic acid nanoparticles to target hepatocytes. Int. J. Pharm. 2009, 371, 163-169. [CrossRef]

134. Maurizi, L.; Papa, A.; Boudon, J.; Sudhakaran, S.; Pruvot, B.; Vandroux, D.; Chluba, J.; Lizard, G.; Millot, N. Toxicological risk assessment of emerging nanomaterials: Cytotoxicity, cellular uptake, effects on biogenesis and cell organelle activity, acute toxicity and biodistribution of oxide nanoparticles. In Unraveling the Safety Profile of Nanoscale Particles and Materials; IntechOpen IntechOpen Limited: London, UK, 2018. [CrossRef]

135. Geppert, M.; Hohnholt, M.C.; Thiel, K.; Nürnberger, S.; Grunwald, I.; Rezwan, K.; Dringen, R. Uptake of dimercaptosuccinatecoated magnetic iron oxide nanoparticles by cultured brain astrocytes. Nanotechnology 2011, 22, 145101. [CrossRef] [PubMed]

136. Lee, N.; Choi, Y.; Lee, Y.; Park, M.; Moon, W.K.; Choi, S.H.; Hyeon, T. Water-dispersible ferrimagnetic iron oxide nanocubes with extremely high $\mathrm{r}_{2}$ relaxivity for highly sensitive in vivo MRI of tumors. Nano Lett. 2012, 12, 3127-3131. [CrossRef]

137. Valdiglesias, V.; Fernández-Bertólez, N.; Kiliç, G.; Costa, C.; Costa, S.; Fraga, S.; Bessa, M.J.; Pásaro, E.; Teixeira, J.P.; Laffon, B. Are iron oxide nanoparticles safe? Current knowledge and future perspectives. J. Trace Elem. Med. Biol. 2016, 38, 53-63. [CrossRef]

138. Azam, A.; Ahmed, A.S.; Oves, M.; Khan, M.S.; Habib, S.S.; Memic, A. Antimicrobial activity of metal oxide nanoparticles against Gram-positive and Gram-negative bacteria: A comparative study. Int. J. Nanomed. 2012, 7, 6003-6009. [CrossRef]

139. Braun, V. Surface signaling: Novel transcription initiation mechanism starting from the cell surface. Arch. Microbiol. 1997, 167, 325-331. [CrossRef] [PubMed]

140. Yasuyuki, M.; Kunihiro, K.; Kurissery, S.; Kanavillil, N.; Sato, Y.; Kikuchi, Y. Antibacterial properties of nine pure metals: A laboratory study using Staphylococcus aureus and Escherichia coli. Biofouling. J. Bioadhes. Biofilm Res. 2010, 26, 851-858. [CrossRef] [PubMed]

141. Apopa, P.L.; Qian, Y.; Shao, R.; Guo, N.L.; Schwegler-Berry, D.; Pacurari, M.; Porter, D.; Shi, X.; Vallyathan, V.; Castranova, V.; et al. Iron oxide nanoparticles induce human microvascular endothelial cell permeability through reactive oxygen species production and microtubule remodeling. Part. Fibre Toxicol. 2009, 6, 1. [CrossRef] [PubMed]

142. Singh, N.; Jenkins, G.J.; Asadi, R.; Doak, S.H. Potential toxicity of superparamagnetic iron oxide nanoparticles (SPION). Nano Rev. 2010, 1, 5358. [CrossRef]

143. Yarjanli, Z.; Ghaedi, K.; Esmaeili, A.; Rahgozar, S.; Zarrabi, A. Iron oxide nanoparticles may damage to the neural tissue through iron accumulation, oxidative stress, and protein aggregation. BMC Neurosci. 2017, 18, 51. [CrossRef]

144. Dwivedi, S.; Siddiqui, M.A.; Farshori, N.N.; Ahamed, M.; Musarrat, J.; Al-Khedhairy, A.A. Synthesis, characterization and toxicological evaluation of iron oxide nanoparticles in human lung alveolar epithelial cells. Colloids Surf. B Biointerfaces 2014, 122, 209-215. [CrossRef]

145. Wei, Y.; Zhao, M.; Yang, F.; Mao, Y.; Xie, H.; Zhou, Q. Iron overload by superparamagnetic iron oxide nanoparticles is a high risk factor in cirrhosis by a systems toxicology assessment. Sci. Rep. 2016, 6, 29110. [CrossRef]

146. Petros, R.A.; DeSimone, J.M. Strategies in the design of nanoparticles for therapeutic applications. Nat. Rev. Drug Discov. 2010, 9 , 615-627. [CrossRef]

147. Grainger, D.W. Connecting drug delivery reality to smart materials design. Int. J. Pharm. 2013, 454, 521-524. [CrossRef] 
148. Pelaz, B.; del Pino, P.; Maffre, P.; Hartmann, R.; Gallego, M.; Rivera-Fernández, S.; de la Fuente, J.M.; Nienhaus, G.U.; Parak, W.J. Surface Functionalization of Nanoparticles with Polyethylene Glycol: Effects on Protein Adsorption and Cellular Uptake. ACS Nano 2015, 9, 6996-7008. [CrossRef]

149. Zhang, Y.; Kohler, N.; Zhang, M. Surface modification of superparamagnetic magnetite nanoparticles and their intracellular uptake. Biomaterials 2002, 23, 1553-1561. [CrossRef]

150. Xie, J.; Xu, C.; Kohler, N.; Hou, Y.; Sun, S. Controlled PEGylation of monodisperse $\mathrm{Fe}_{3} \mathrm{O}_{4}$ nanoparticles for reduced non-specific uptake by macrophage cells. Adv. Mater. 2007, 19, 3163-3166. [CrossRef]

151. Yu, S.; Perálvarez-Marín, A.; Minelli, C.; Faraudo, J.; Roig, A.; Laromaine, A. Albumin-coated SPIONs: An experimental and theoretical evaluation of protein conformation, binding affinity and competition with serum proteins. Nanoscale 2016, 8 , 14393-14405. [CrossRef]

152. Kalidasan, V.; Liu, X.L.; Herng, T.S.; Yang, Y.; Ding, J. Bovine Serum Albumin-Conjugated Ferrimagnetic Iron Oxide Nanoparticles to Enhance the Biocompatibility and Magnetic Hyperthermia Performance. Nanomicro Lett. 2016, 8, 80-93. [CrossRef] [PubMed]

153. Maffre, P.; Brandholt, S.; Nienhaus, K.; Shang, L.; Parak, W.J.; Nienhaus, G.U. Effects of surface functionalization on the adsorption of human serum albumin onto nanoparticles-A fluorescence correlation spectroscopy study. Beilstein J. Nanotechnol. 2014, 5, 2036-2047. [CrossRef] [PubMed] 